\title{
Water, energy and land insecurity in global supply chains
}

1 Abstract: National consumption of goods and services is met by domestic production and

2 international trade. As a result, countries and sectors exert pressure on natural resources

3 both within and beyond their national borders. Where this resource demand is imposed

4 matters to the effective management of global resource insecurity. Although instructive, the

${ }_{5}$ 'resource footprint' of a country or sector - a common yardstick to assess the sustainability of

6 consumption in relation to water, energy and land systems - does not distinguish its origin

7 of production and associated resource risk. As a result, the source and severity of global

8 resource insecurity remains poorly understood. To understand how resource use connects

9 different actors within the global economy, the water, energy and land footprints of 189

10 countries and 14838 country sectors are partitioned by source (domestic, macro-regional

11 and remote) and risk (high, medium and low). Linking national consumption to source

12 reveals countries and sectors are highly exposed, directly (via domestic production) and

13 indirectly (via imports), to over-exploited, insecure, and degraded water, energy, and land

14 resources. However, countries and sectors exhibit greater exposure to resource risks via

15 international trade $(\approx 80-90 \%)$, mainly from remote production sources. Within this context,

16 countries and sectors share the same sources of resource supply and risk, highlighting an

17 opportunity to manage their resource security by intervening in upstream global supply

18 chains. Nevertheless, our findings also invite critical reflection on whether globalisation is

19 compatible with managing risks countries face and drive across the global water-energy-land

20 system. 


\section{Introduction}

A minimum condition of sustainable development is that demand for goods and services is met without compromising the resource base on which they depend (Hickel and Kallis, 2019). However, both in individual countries, and globally, such a condition has not been met (Erb et al., 2012; Krausmann et al., 2018; Steffen et al., 2015). Instead, development has begun to overstep the limited regenerative and assimilative capacities of the biosphere (O'Neill et al., 2018). This is observable for three critical resources which underpin development: water (Gleick and Heberger, 2014), energy (Seppelt et al., 2014), and land (IPBES, 2018). The impact of human activity across the Water-Energy-Land (WEL) system is unprecedented within history (Steffen et al., 2015). Major water basins have been over-exploited (Wang and Zimmerman, 2016), some at fifty times their replenishment rate (Tuninetti et al., 2019), resulting in an estimated four billion people affected by severe water scarcity (Mekonnen and Hoekstra, 2016). Global energy demand, primarily for fossil fuel resources, has brought humanity dangerously close to tipping points in the climate system whilst also curtailing national security (Andrews-Speed et al., 2012; IPCC, 2014). Over three-quarters of potentially productive land has been degraded (IPBES, 2018), driving food insecurity and collapse of ecosystems (Chaudhary and Kastner, 2016; FAO, 2011; Wilting et al., 2017). The factors contributing towards this trilemma - economic development, population growth and technological change - are abundantly clear. However, the exact pathways of water, energy and land resource insecurity have become increasingly complex to unpick, sort, and reconcile with meaningful policy interventions.

In recent decades, resource pressures have shifted from local to global production and consumption contexts (Giampietro, 2014). Consequently, local resource problems related to water stress (Allan, 2003; Dalin et al., 2017; Lenzen et al., 2013a; Vörösmarty et al., 2015), energy demand (Davis and Caldeira, 2010; Kander et al., 2015; Zhang et al., 2017) and land degradation (Bruckner et al., 2015; Chen and Han, 2015; Godar et al., 2015), are increasingly determined by consumptive decisions made beyond national borders. This can be observed in the rise of trade in agriculture and livestock products (MacDonald et al., 2015; Taherzadeh and Caro, 2019; Zanten et al., 2016), fossil fuels (Davis and Caldeira, 2010), manufactured goods (Zhang et al., 2017), and services (Victor and Rosenbluth, 2007).

The overall resource burden of human activity has also grown dramatically. During the 20th century, global population quadrupled and global economic output grew more than 20-fold 
(Maddison, 2001). This expansion saw the extraction of construction materials grow by a factor of 34 , ores and minerals by a factor of 27 , fossil fuels by a factor of 12 , and biomass by a factor of 3.6 (Krausmann et al., 2009). Moreover, the number of competing demands for water, energy and land resources have grown, in step with the increasing diversity of goods and services consumed within society. New demands on natural resources, from the built environment, transport sector, and consumer goods, have accompanied the shift of societies from agrarian to industrial regimes (Krausmann et al., 2016). These many pathways of water, energy and land use have also become fragmented along supply chains owing to the outsourcing and sub-contracting of production (Los et al., 2015).

Several methods of analysis have emerged to better characterise the increasingly complex and globalised pathways of human influence across the WEL system. Early life-cycle analysis studies of product supply chains showed how the extraction and use of natural resources is highly interconnected within complex networks of sectoral interactions and feedbacks (Alting and Jøgensen, 1993; Ayres et al., 1998; Hendrickson et al., 1998). Economy-wide environmental footprinting later illustrated the macro-economic nature of these relationships, rendering country and sector resource dependencies global in scope (Bringezu et al., 2003; Lenzen, 2008; Suh et al., 2004). Within this context, several studies have highlighted how resource-related risks, via international trade, are transmitted between both developed and developing countries (Allan, 2010; Guan and Hubacek, 2007; Kumar and Singh, 2005). The 2008 global food crisis exemplified the tight embrace between these forces (Headey, 2011). More recently, practical developments in data availability have enabled the development of several environmental indicators for the purpose of multiple appraisal of country and sector consumption ( $c f$ Fang et al., 2014; Galli et al., 2012; O'Neill et al., 2018; Wood et al., 2018). Better integration of risks and planetary boundaries into environmental footprinting has helped to identify key drivers of resource insecurity (Dao et al., 2018; Fang et al., 2014, 2015a,b; Lenzen et al., 2013a; Li et al., 2019; O'Neill et al., 2018). However, due to the limited spatial and sectoral scope of risk-based environmental footprinting, systemic drivers of resource insecurity in the world economy remain poorly understood.

Case studies have served as the dominant approach to assess source across the waterenergy-land (WEL) system. However, boundaries for such analysis are usually established without a foundational understanding of major resource origins and risks across the WEL system which are global and cross-sectoral in scope. Consequently, policy priorities drawn from resource security assessment might simply be an artefact of the partial scope of analysis 
rather than a reflection of systemic risks to natural resource systems and the activities which they support (Srivastava and Lyla, 2014). As a result, many have called for resource use analysis to be broadened, sectorally and spatially, to encompass the totality of global water, energy and land use (Carmona-Moreno et al., 2019; Hoff and Gerten, 2015; Johnson et al., 2019; Staupe-Delgado, 2019; Sušnik, 2018; Taherzadeh et al., 2018; Vivanco et al., 2018b; Weitz et al., 2017; Wichelns, 2017). Only with this systematic overview can priorities for management of natural resources be meaningfully compared.

Attempts to broaden the scope of integrated environmental impact assessment remain limited to global models of the food sector (FAO, 2015; Keskinen et al., 2016; Lacirignola et al., 2014; Sušnik, 2018), cross-sectoral analysis of single countries or regions (Duan and Chen, 2017; Owen et al., 2018; Peng et al., 2019; Tukker et al., 2016), or global, crosssectoral models which capture total national and sectoral resource use but do not distinguish its associated risk (Bijl et al., 2018; Velázquez et al., 2010; Vivanco et al., 2018a; White et al., 2018). Accordingly, there is a need for a flexible framework for resource use assessment which captures the major interactions and risks across the WEL system, and which is global and cross-sectoral in scope.

By developing a spatial and risk-weighted assessment of interactions between the world economy and global water-energy-land system, this study examines:

1. the level of country and sector dependence on global water, energy and land resources;

2. the severity and source of national and sectoral water, energy and land use and risk exposure; and

3. implications of national boundary setting for resource security assessment

Insights from this analysis can inform resource security assessment in three main ways. First, by studying how resource use connects different actors within the global economy, this analysis identifies the appropriate unit of spatial analysis (national, macro-regional or global) for the integrated management of consumption pressures on water, energy and land resources. Second, by linking consumption to source, this analysis reveals the main sources of resource extraction and risk embodied in national and sectoral supply chains, which in turn helps to identify otherwise unforeseen hot-spots for policy focus (Green et al., 2016). Third, this analysis brings into sharper focus the implications of national-scale resource security assessment of countries and sectors by revealing the resource use and risk ignored 
by only focusing analysis within national borders. In addition to contributing towards the identification of future research and policy priorities in resource security assessment, this study furthers understanding of national and sectoral dependence on, and exposure to, over-exploited, insecure, and degraded water, energy, and land resources.

The study begins by discussing the state of resource use assessment in relation to spatial coverage and boundary setting. This is followed by a summary of the analytical framework and indicators used to distinguish the national self-sufficiency and global inter-dependency of countries and sectors in relation to water, energy and land resources. A complementary schema of resource risk is developed in order to evaluate the severity of water, energy and land use embodied in national and sectoral supply chains, and the supra-national extent of these interactions. The insights from this analysis are reported at an aggregate scale to reflect on and respond to the need for a high-level understanding of the importance of different scales (national, macro-regional and global) at which resource use assessment may be undertaken. However, country case studies are used to illustrate noteworthy findings. A major challenge pertaining to the assessment of national resource insecurity concerns its variability within countries which can be larger than differences between whole countries. Whilst the lack of sub-national resource use and risk data prevents a meaningful analysis of national resource insecurity at such level, we down-scale the basic model used in this paper to examine these effects and present a framework for further analysis as higher resolution data becomes available. The study concludes by discussing the relative importance of global-scale analysis to the study of the water-energy-land system in different contexts.

\section{Methods and Data}

Boundaries of resource use analysis and governance should be informed by a comprehensive understanding of the total environmental burden of human activity as it emerges from analysis of the data. However, current resource use assessment sets these boundaries a priori, often truncating accounting of water, energy and land use both sectorally and spatially (Taherzadeh et al., 2018). This is exemplified most clearly in the conceptual and empirical scope of the water-energy-food nexus concept which has tended to limit resource use assessment to the food sector and domestic production, as noted in several recent reviews of this emerging research and policy agenda ( $c f$ Endo et al., 2015; Green et al., 2016; Leck et al., 2015; Liu 
et al., 2015). Indeed, several models for 'nexus-based assessment', do not extend to the entire global water, energy and land network ( $c f$ Daher and Mohtar, 2015; FAO, 2015; Giampietro, 2014; SEI, 2012). As such, there is a clear need for methods of resource use assessment which accommodate multi-regional and cross-sectoral analysis of national resource use.

Multi-Regional Input Output Analysis (MRIOA) offers a disciplined methodological framework within this context (Albrecht et al., 2018). MRIOA evaluates how the demand of a sector or country is distributed throughout the global economy based on financial transactions between sectors, and enumerates the production and associated resource requirements arising from these estimated dependencies. Such a method enables a comprehensive coverage of resource demand embodied in international supply chains at a sector-wide or economy-wide scale owing to the completeness of national economic and environmental accounts (Tukker and Dietzenbacher, 2013). This study develops a modelling framework based on MRIOA accounting and data to evaluate the spatial distribution and severity of water, energy and land use driven by countries and sectors. Since the main components of MRIOA are well documented elsewhere ( $c f$ Isard, 1951; Leontief and Strout, 1963; Miller and Blair, 2009), we only recapitulate the extensions to MRIOA used in this study (see Section 2.3).

\subsection{Boundary setting and resource footprinting}

The importance of boundary setting to the evaluation of country and sector resource footprints is exemplified by the numerous interlinkages and trade flows which redistribute the environmental burdens of production and consumption beyond national borders (Wiedmann and Lenzen, 2018). However, whilst the globalised nature of supply chains is often used to justify global-scale analysis of resource footprinting, the underlying production and resource origins of country and sector footprints remains poorly understood (Bijl et al., 2018). Moreover, the binary treatment of country or sector resource footprints as national or global ignores the significance of intra-regional country and sector inter-dependencies as a spatial unit of natural resource accounting and management. Distinguishing the source of non-domestic resource dependencies is important for several reasons. First, different scales of analysis entail vastly different levels of methodological complexity and data requirement for resource use assessment. Second, intra-regional resource footprinting implicates policy actors and communities that are overlooked in current global-scale assessment. Indeed, better alignment between units of resource use assessment and governance might exist at the macro-regional scale due 
to the plethora of bilateral and multi-lateral trade agreements which determine terms of trade between proximate nations (Morin et al., 2019; Taherzadeh, 2019). Lastly, countries within a given region are likely to share similar environmental conditions which might compound the exposure of countries or sectors to resource risks in times of macro-regional resource degradation or scarcity. To address these gaps in understanding of the spatial distribution of country and sector resource footprints, this study evaluates water, energy and land use associated with countries and sectors at national, intra-regional (hereafter 'macro-regional'), and supra-regional (hereafter 'remote') scales.

\subsection{Linking resource use to source}

National resource footprinting, whether undertaken by physical trade flow analysis or MRIOA, indicates the overall burden of a coun consumption within a given domain e.g. water, energy, and land. However, by treating resource demand imposed in different countries as homogeneous, the resource footprint does not readily distinguish between the source and relative risk associated with a country's resource footprint. Ostensibly, two countries could have a similar overall resource footprint but exhibit a large variation in their exposure to resource-related risks owing to differences between the sustainability associated with the resource base on which they depend. Moreover, two countries could face a similar level of resource-related risk, but from different sources; one country highly exposed to resource risks via domestic production and another from trade. By contextualising resource footprint assessment by severity and source it is possible to understand and potentially manage the environmental burden of countries and sectors across different spatial scales. Such a disaggregation is employed in this study in order to establish the scale and severity of country and sector resource use across the WEL system.

\subsection{Modelling framework}

Consumption-based water, energy and land footprints were calculated for 189 countries, and 19 global regions using the standard Leontief demand-pull model, across an MRIO table capturing inter-industry trade amongst 14838 sectors. The resultant resource footprints and associated resource fluxes were partitioned in two ways. First, country and sector footprints were analysed in relation to three spatial boundaries: national, macro-regional (e.g. South- 
East Asia or Western Europe) and global. Second, indices designed to capture insecure water, energy, and land resource use were used to estimate the dependence of countries and sectors on high risk resource use at different spatial scales.

The partitioning of country and sector footprints by spatial scale was achieved by applying a series of masks - arrays of ones and zeros - to the resource requirements matrix of each country and region to assess their domestic (diagonal), non-domestic (off-diagonal), and macro-regional (manually constructed from UN et al. (2009) classifications) consumptionbased resource footprint. This revealed the importance of national, macro-regional and global boundary setting for resource use assessment of countries and sectors.

The partitioning of country and sector by resource-related risks followed a similar approach. Within the context of this assessment, resource risk is defined as:

Dependence of countries, sectors or consumers on natural resource use characterised by current environmental and/or political insecurity.

This narrow conception of resource risk reflects the limited availability of data pertaining to other potentially more meaningful determinants of resource insecurity for countries and sectors contained within this assessment, such as adaptive capacity (Folke, 2016; Govindan et al., 2014; Tukamuhabwa et al., 2015), time frame of resource insecurity (Behzadi et al., 2018; Heckmann et al., 2015; Snyder et al., 2016), and organisational influence (Fayezi et al., 2012; Friday et al., 2018; Varsei et al., 2014), which might help to imply the extent of risk propagation, risk duration, risk sharing and related risk exposure of actors across supply networks. Indeed, the nature of resource insecurity and its relation to risk is multifaceted, as noted by past attempts to characterise water security (Cook and Bakker, 2012; Jepson et al., 2017; Kumar, 2015), energy security (Cherp and Jewell, 2014; Le et al., 2019; Månsson et al., 2014) and land security (Elgert, 2016; FAO, 2011; Lambin and Meyfroidt, 2011). Lack of access to natural resources also affects the provision of goods, services and basic needs depending on the resource system concerned, preventing a unifying theory of resource insecurity and its impacts (Wutich and Brewis, 2014). Resource ownership and governance, whilst critical in terms of resource access, are also not fully captured in prevailing risk indices. However, the flexible methodological framework employed in this study is able to accommodate different measurements and multi-dimensional aspects of resource risk. As more detailed temporal and spatial economic and environmental data becomes available, modelling of the 
exact relationships between country resource footprints and resource insecurity, currently not possible with national- and annual-level reporting, will become feasible (Moran et al., 2020).

The decision to model and quantify the extent of resource insecurity within the WEL system acts to reinforce the already dominant paradigm of quantitative assessment in the study and management of natural resource systems (Stirling, 2015). By framing the problem space of natural resource use in purely numeric terms, there is a propensity to encourage an apolitical view of the drivers, consequences and possible remedies linked to overexploitation of water, energy and land resources. For example, MRIOA and similar techniques do not readily expose the links between inequality and resource use which derive from uneven historical development within and between countries and regions of the world economy. Moreover, the lock-in of countries to unsustainable patterns of resource extraction is not merely a consequence of societal choice but a product of national and international policy regimes which have often benefited from the exploitation of natural resources without direct exposure to its consequences (Allouche et al., 2015; Siegfried et al., 2008; Srivastava et al., 2017). Nevertheless, given the limited understanding of how resource-related risks connect different actors across the global WEL system (Wiedmann and Lenzen, 2018), the explanatory power of an assessment borne from a simple definition of resource security can still be instructive for the identification of new research and policy priorities surrounding sustainable resource use. Attempting such assessment can help to identify important methodological challenges and data gaps for the assessment of supply chain resilience, and the resource security of consumption patterns across a large number of countries and sectors. This is an increasingly important priority for national governments and businesses (WEF, 2019).

The resource risk indices used in this assessment, described in Section 2.4, capture qualitative differences in the sustainability and stability of water, energy and land use in different country contexts. This enables 'risk tagging' of resource flows embodied in national and sectoral supply chains (Figure 1). To help convey and compare the resource risk profile of different countries and sectors, resource risk categories, 'high', 'medium', and 'low' were assigned to countries based on whether they ranked in the top, middle, or bottom third of resource risk indices respectively. An overview of this methodological procedure and the data concerned is summarised in Figure 1. 
Formulaically, the source and severity of country and sector resource footprints are calculated as follows:

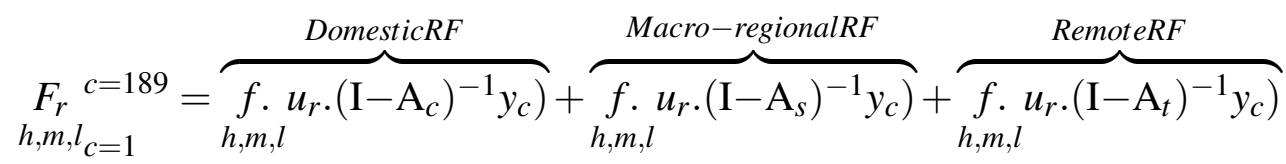

where $F_{r_{h, m, l}}$ refers to the high, medium and low risk footprint of a given country, $c$, for a given resource $r$ (i.e. water, energy or land); $x$ is a column vector of intermediate output in a given country $\left(x_{c}\right)$, its macro-region $\left(x_{s}\right)$ or its remote trading partners $\left(x_{t}\right)$; $\mathrm{A}$ is the direct requirements matrix of a given country $\left(A_{c}\right)$, its macro-region $\left(A_{s}\right)$ or its remote trading partners $\left(\mathrm{A}_{\mathrm{t}}\right) ; I$ represents an identity matrix of the same dimensions; $y_{c}$ is the final demand for domestically produced commodities and services in a given country, $c ; u$ represents an intensity coefficient for a given resource use, $r$, in each sector; and, $f_{h, m, l}$ refer to a mask vector (of ones and zeros) to filter high, medium and low risk production and associated resource use, as defined by Equation 2. Equation 1 can be manipulated to make a macro-region or sector the subject of assessment, as shown in Figures 4 and 7 respectively.

Resource risk masks were calculated to filter country resource footprints by partitioning raw country resource risk index values, described in Section 2.4, into high, medium and low risk:

$$
\underset{0,1}{f_{c}}=\left[R I_{c} \geq \frac{R I^{\max } \cdot i-R I^{\max }}{3}\right] \cdot\left[R I_{c} \leq \frac{R I^{\max } \cdot i}{3}\right]
$$

where $f_{c}$ is a 'mask' value of ' 0 ' or ' 1 ' to indicate whether the production of a country, $c$, falls within a given risk category; $i$ is a given risk category (high $=3$, medium $=2$, low $=1$ ) which can be adjusted to change the level and number of risk categories used to filter national resource footprints; $R I$ is the raw index value data for a country, $c$; and $\mathrm{RI}^{\mathrm{max}}$ is the highest risk value within each index denoting the most resource insecure country, used to assign each country within the low-medium-high risk schema outlined in Figure 1. Equivalent sectoral masks were computed for sectors on the assumption that they faced the same level of resource risk assigned to their country; this was necessary given the lack of sector-specific resource risk data available. 


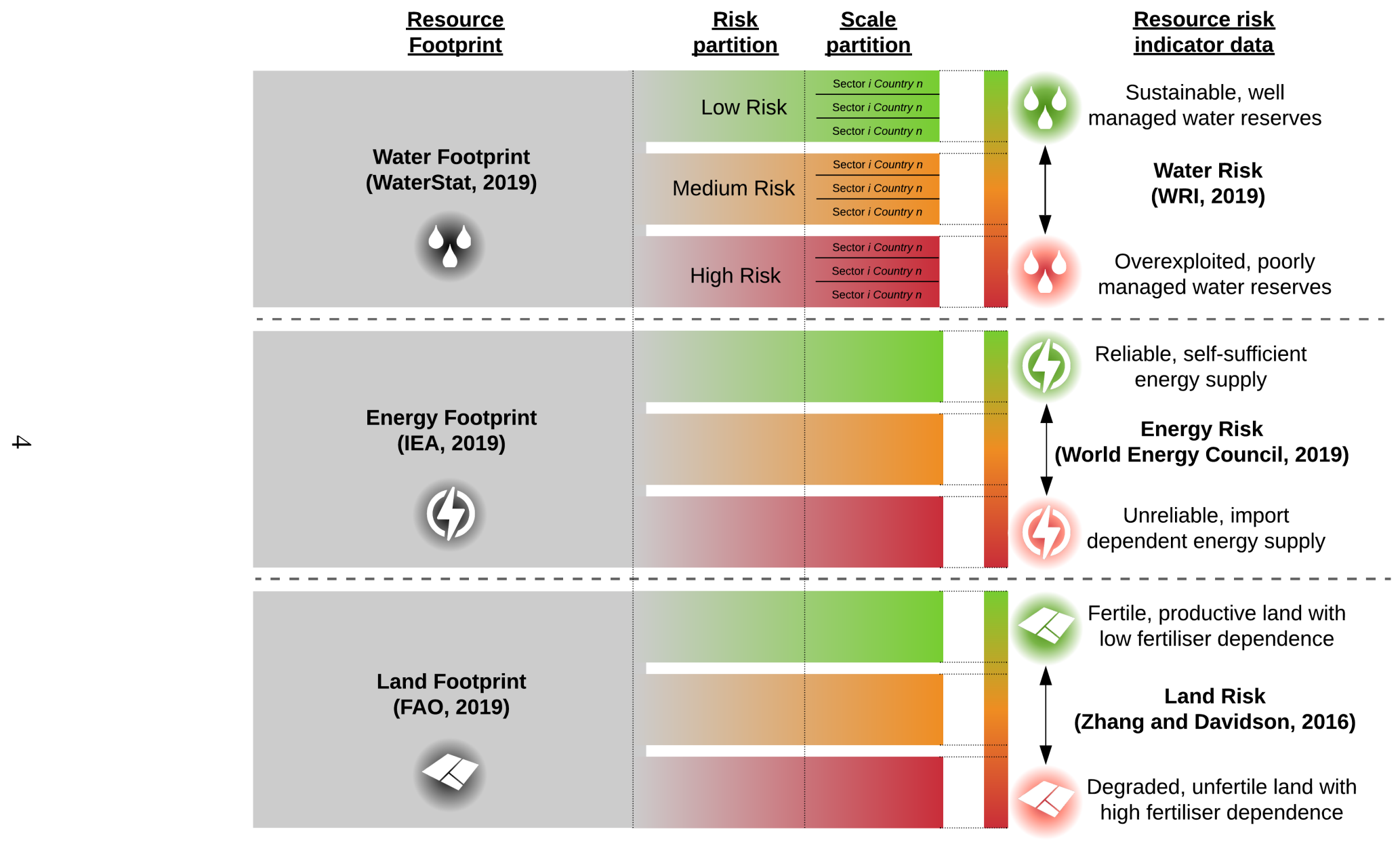

Figure 1 Partitioning resource footprints by spatial scale and risk level

Conceptual diagram illustrating the workflow and data involved in risk and scale partitioning of country and sector resource footprints with references to resource use and risk datasets 


\subsection{Data}

Several MRIOA databases exist for the purpose of economy-wide resource footprinting. Within this study the Eora (2019) MRIO database, developed by Lenzen et al. (2012), is used for its superior sectoral resolution, temporal coverage, and integration with environmental datasets. The full and latest version of the Eora (2019) database captures production, consumption and trade relationships between 189 countries and 14838 country sectors between 1990 and 2015 .

Several criteria informed the selection of resource use and resource risk indicators. These included (i) country and sectoral coverage, (ii) scope in relation to pressures facing water, energy and land systems, (iii) data access, and (iv) data format. An ideal indicator is one with good alignment with the countries and sectors within the Eora (2019) database, meaningful coverage of pressures on resource systems, reliance on open-access and time-proofed data, and minimal processing required before integration with the model.

A concordance of physical environmental accounts of sectoral resource use with national economic accounts in the Eora (2019) database by Lenzen et al. (2012) provided an integrated framework for undertaking water, energy and land footprinting of countries and sectors without the problems of double counting and boundary setting common to use of external environmental datasets (OECD, 2003). However, since data to infer risks associated with water, energy and land use are not readily integrated into MRIOA databases, these were sourced from external sources and linked to the model following the steps explained in Section 2.3.

Water use data were sourced from WaterStat (2019), the world's most comprehensive water footprint database, which compiles agricultural and industrial water use data for countries and sector. The database, developed by Hoekstra and Wiedmann (2014), relies principally on data from the UN FAO which reports member countries' agricultural water use through a yearly survey administered by their national authorities (Mateo-Sagasta and Salian, 2012). The water use of industrial commodities relies on data from FAO (2020) and Eurostat (2020) and is further elaborated in Hoekstra and Mekonnen (2011). A given sector's production-based water footprint accounts for its direct blue water use (from groundwater and aquifers) and green water use (precipitation and evapo-transpiration); these were aggregated to evaluate the total consumption-based footprint of countries. Since WaterStat (2019) only covers national and sectoral water use between 1990-2005, data were scaled by annual 
sectoral production, consumption and trade expenditure in the Eora (2019) database in order to calculate consumption-based water footprints for other years.

Many indicators have been proposed to evaluate the sustainability of water use. Measures of blue and green water scarcity, water quality, environmental flow requirements, economic access to water, and water regulation standards have received greatest attention within scientific and policy communities (Vollmer et al., 2016). Within this assessment, an indicator of projected national blue water scarcity under a near-term (2020) business-as-usual climate scenario, sourced from WRI (2015), is used to infer country-level water risk. Although use of a single water risk indicator may not reflect the multi-dimensional nature of threats associated with national water use, there are several justifications for its use. First, in contrast to green water, blue water sources are often non-renewable and so their over-exploitation poses a more acute threat to water users. Second, as a point source resource stock, blue water can be readily managed via pricing and regulation. Third, blue water scarcity is the agreed metric to assess progress against the water-related UN Sustainable Development Goals (Vanham et al., 2018); this enables direct policy application of the analysis within this study.

Energy use data were sourced from the International Energy Agency which reports total energy use by sector from twelve sources: natural gas, coal, petroleum, nuclear, hydroelectric, geothermal, wind, solar, tide, wave, biomass, and waste based on annual questionnaires of countries (IEA, 2019). Energy risk data were sourced from the World Energy Council (2018) Energy Index which ranks countries' energy security according to their effective management of primary energy supply from domestic and external sources, reliability of energy infrastructure, and ability of energy providers to meet current and future demand. In contrast to the water and land risk indicators which measure the environmental sustainability of resource, the energy risk indicator did not measure the environmental sustainability of national energy use since such a metric (such as the proportion of renewable energy production in national energy mix) does not meaningfully capture energy (in)security and related risks.

Land use data were compiled by the UN Food and Agriculture Organization (FAO, 2019) and capture the extent of land under cultivation for 172 crops based on data reported by member countries' national authorities through annual questionnaires of "land use, irrigation and agricultural practices". Land risk data is based on a the Sustainable Nitrogen Management Index (SNMI), developed by Zhang and Davidson (2016) based on data from FAO (2019) and compiled by University (2019) for 2010. The SNMI provides a proxy for the productivity and 
sustainability of agricultural land use, based on (i) the fraction of nitrogen input harvested as product (i.e. nitrogen use efficiency, as defined in Zhang et al. (2015) and (ii) land use efficiency (i.e. harvested nitrogen). A agricultural land risk indicator was chosen instead of an ecosystem or natural hazard risk measure because it directly captured the sustainability of national land footprints, as measured by crop and livestock land area, offers clear management implications (e.g. improving soil fertiliser and fertiliser overuse), and relies on data which is widely available for a large number of countries (165 of 189 analysed).

An unclassified category was assigned to resource-related use in countries which were not measured by the risk indices used. Overall, $0.42 \%$ of global water use, $3.78 \%$ of global energy use and $2.07 \%$ of global land use were unclassified by the risk indicator datasets used. Meanwhile, the lack of temporal concordance between resource use and risk data and economic accounts meant the assessment of national water, energy and land footprints in this study assumed no change in resource efficiency or resource insecurity for time periods where data is missing (e.g. for water footprints after 2005 or water and land insecurity after 2010). This has direct implications for the quantification of national and sectoral resource footprints and their relative risk. For example, by ignoring (mostly positive) trends in water use efficiency noted in other studies ( $c f$ Cai et al., 2019; Flörke et al., 2013; Zhou et al., 2020), estimates of country and sector water footprints and risk may exceed their actual value. However, the relationship between resource efficiency and resource risk is complex and we are unable to conclude that the latter will improve as a result of the former (Duro et al., 2020; Freire-González, 2019; Long et al., 2017).

In future, such assumptions can be relaxed as the temporal coverage of economic and environmental data improves Dietzenbacher et al. (2013).

\section{Analysis}

This section presents the decomposition of country and sector water, energy and land footprints by resource risk and spatial scale in 2015. Section 3.1 presents a resource footprint and risk profile of countries and sectors in relation to water, energy and land. Section 3.2 distinguishes the contribution of domestic and non-domestic resource use within this context. Section 3.3 examines the challenges and potential effects of incorporating sub-national resource use and risk data into this study's modelling of national water insecurity. 


\subsection{Country and sector risks across the WEL system}

Profiles of country exposure to resource risk vary with respect to water, energy, and land. Figure 2 presents the overall distribution of national dependence on low, medium and high risk water, energy, and land use for all 189 countries analysed. The risk profile of country water and energy footprints appear somewhat closer than land to what may be desirable a high level of dependence on low risk resource use and low level of dependence on high risk resource use - as illustrated by the key in Figure 2 - but do not imply a high proportion of countries are water or energy secure. The risk profile of land use suggests lower levels of national dependence on low risk land use and higher levels of dependence on high risk land use. All three resource risk profiles exhibit a bi-modal distribution which highlights a partition of countries into one of two groups: resource secure and resource insecure.

Whilst the overall landscape of national resource risks is concerning, several countries are noteworthy within this context. Figure 3 illustrates the absolute volume of high risk and low risk water use (in $\mathrm{Gm}^{3}$ ), energy use (in $\mathrm{TJ}$ ) and land use (ha) embodied in (A) national $(n=189)$ and $(B)$ macro-regional $(n=19)$ consumption. This global landscape of resource-related dependence captures several features of national exposure to resource risk. First, many countries exhibit greater dependence on high risk resource use than low risk resource use, as indicated by their position right of the 1-1 lines of equality in Figure 3; this corresponds to water use in 39 countries, energy use in 32 countries, and land use in 81 countries. Several countries even appear to suffer a double burden $(n=22)$ or triple burden (Algeria, Lebanon, Morocco and Pakistan), dependence on high risk resource use across more than one resource.

However, risk-based profiling of individual countries' resource footprints reveals that most countries experience both different sources and levels of exposure to water, energy and land risks. For example, the USA exhibits the highest dependence (92\%) of any country on high risk land use, chiefly (96.4\%) from its own domestic production; is moderately (around 50\%) dependent on high risk water use, mainly from Mexico (34\%), India (27\%) and Pakistan (13\%); but relies primarily (86.6\%) on low risk energy use. Nevertheless, in absolute terms, the USA's high risk energy use is among the highest of any country modelled, as shown in Table 1, due to its high per capita energy use and population (Figure 2). In contrast, India exhibits minimal ( $>1 \%$ ) exposure to high risk land use but is the most highly dependent country on high risk water use (94.5\%), almost wholly (99\%) due to its own domestic high 
risk water use. The discrepancy between water and land risk profiles of countries is explained by most of the major high risk land use countries and exporters (e.g. Argentina, Brazil, USA and Canada) being categorised as medium-low water risk based on the risk indices used.

Table 1 Top five countries by high risk resource footprint

\begin{tabular}{ccc}
\hline high-risk water footprint & high-risk energy footprint & high-risk land footprint \\
\hline India & Thailand & USA \\
Pakistan & Egypt & Brazil \\
Mexico & Pakistan & Ukraine \\
Turkey & USA & Canada \\
Iran & Bangladesh & China \\
\hline
\end{tabular}

The advantages of a risk-based approach to resource footprinting is also apparent when comparing two countries with a similar overall footprint, indicated by circle size in Figure 3A. The USA and China have similar overall energy and land footprints, however China exhibits lower reliance $(6.2 \%)$ on low risk energy compared with the USA (86.6\%) and the US is more highly exposed (92.6\%) to high risk land use than China (4.2\%). This discrepancy is explained by (i) energy and land use in China being classified as medium risk, (ii) land use and energy use in the USA being classified as high risk and low risk respectively; and, (iii) energy and land footprints in both countries being imposed mainly domestically. However, in other cases, trade plays a much greater role in the transmission of resource insecurity, as shown in Section 3.2. Ranking countries in terms of their high-risk water, energy, and land footprint, instead of their overall footprint, as shown in Table 1 reveals countries which have received less attention in resource-related research and policy to date. Although not featured in the top countries by absolute resource footprint (USA, China, India, Brazil, Russia and Japan), Pakistan, Mexico, Turkey, Iran, Thailand, Egypt, Bangladesh, Ukraine and Canada are found to be globally important within the context of high risk resource use (Table 1).

At a macro-scale, global regions were also found to be acutely exposed to water, energy and land risk (Figure 3). Central, Southern and Western Asia showed the highest dependence, on high risk water use (70-90\%). In terms of energy, Northern Africa was highly exposed to sources of high energy risk $(>75 \%)$, however the remaining 18 regions were more energy secure with dependence on high risk energy ranging between 0.4 and 20.3\% (mean: $7.14 \%$ ). The Americas (Northern, Southern, and Central America) and Europe (all regions) were highly exposed to land-related risk; meanwhile regions in Asia and Africa had low levels of dependence $(<13 \%)$ on high risk land use. 
Important countries in relation to resource use and associated risks can also be identified by weighting countries' risk-based footprints in relation to the size of their economy and population to assess the average resource burden of (i) an individual consumer and (ii) a dollar spent and (ii) in each country. This analysis reveals major differences between the influence of economic and demographic change on resource use in different countries and global regions. Table 2 shows the top 15 countries $^{1}$ by high risk water, energy and land footprint per capita. The USA exhibits the highest per capita high risk water, energy and land footprint. Other high-income countries also tend to have the highest resource footprint per capita in relation to high risk water, energy and land resources (Figure 3).

\footnotetext{
${ }^{1}$ Countries with a population $<0.5 \%$ of the global total were excluded from Table 2 to reveal only those countries whose per capita resource footprint figures were significant)
} 


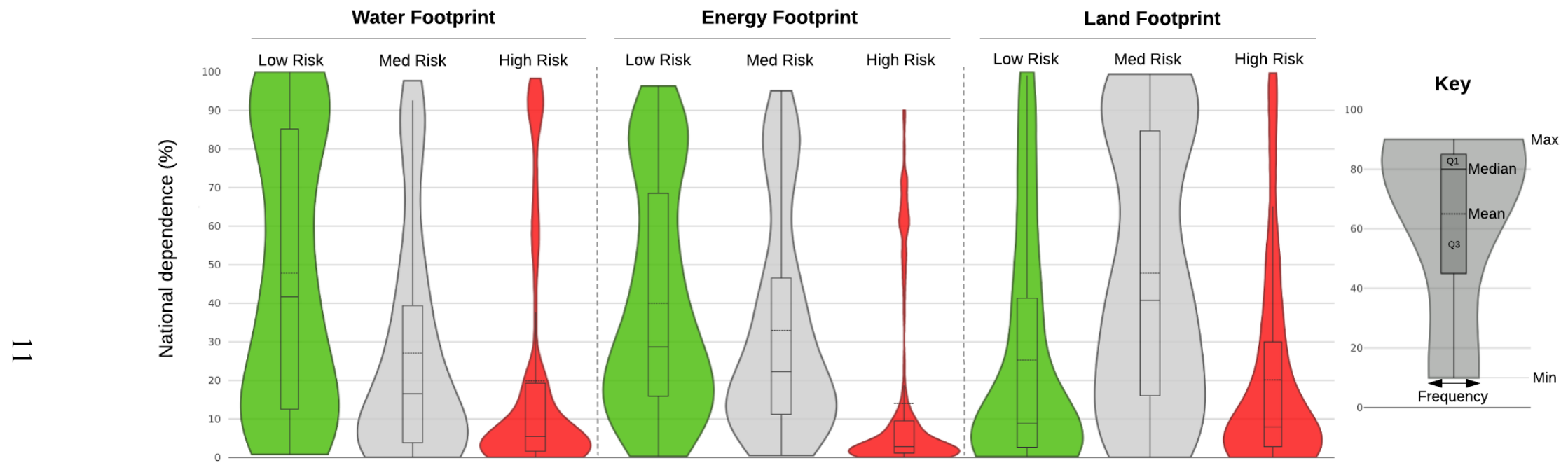

Figure 2 Profile of water energy and land use

Violin and box plots showing the distribution of national consumption (n=189) met by water, energy,and land resources of low and high risk. The width of each violin represents the frequency of countries at a given level of resource risk (green=low, grey=medium, red=high) and proportion of national dependence. Box plots represent the inter-quartile range (Q1, median, Q3). Dashed black lines denote the mean national dependence on water, energy, and land resources at low and high risk. 
A
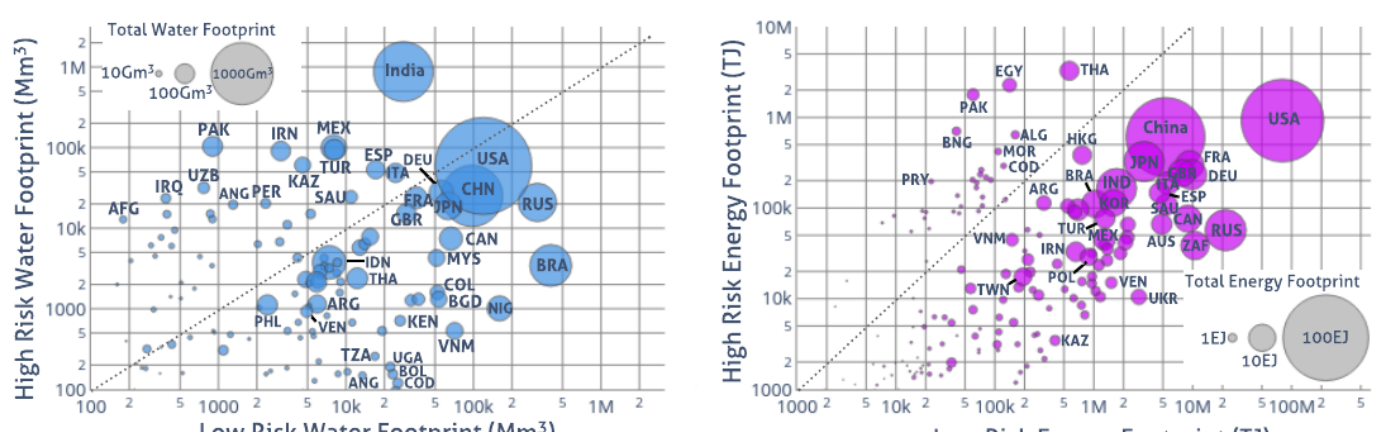

Low Risk Energy Footprint (TJ)

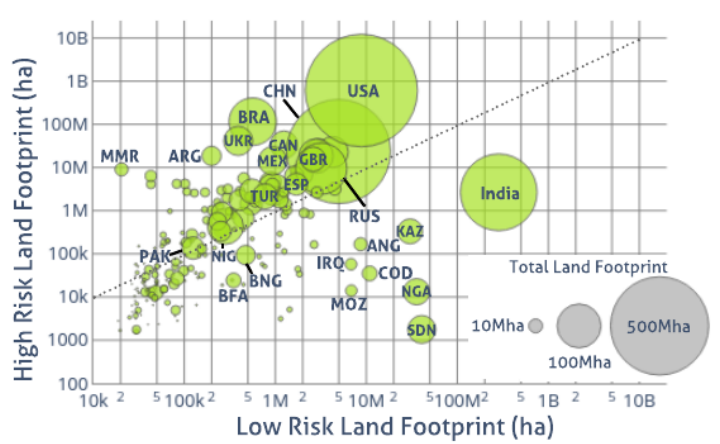

\section{B}
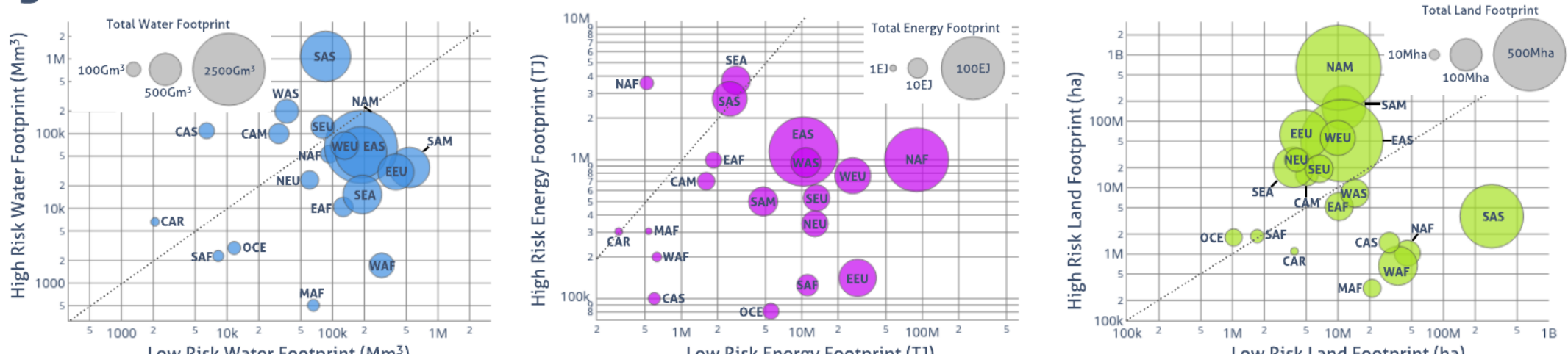

Figure 3 Level of National and Macro-regional Resource Risk

National (A) and macro-regional (B) water, energy, and land footprints decomposed into low risk (x-axis) and high risk (y-axis) components, displayed on a log scale. Circle size represents the overall resource footprint of a nation or region. Macro-region abbreviations - NAF: Northern Africa, EAF: Eastern Africa, MAF: Middle Africa, SAF: Southern Africa, WAF: Western Africa, CAR: Caribbean CAM: Central America, SAM: South America, NAM: Northern America, CAS: Central Asia, EAS: Eastern Asia, SEA: South-eastern Asia, SAS: Southern Asia, WAS: Western Asia, EEU: Eastern Europe, NEU: Northern Europe, SEU: Southern Europe, WEU: Western Europe, OCE: Oceania. 
Table 2 Top 15 countries by quantum of high risk water, energy and land footprint per capita

\begin{tabular}{|c|c|c|c|c|c|}
\hline \multicolumn{2}{|c|}{$\begin{array}{l}\text { High Risk Water Footprint } \\
\text { per capita }\left(\mathbf{m}^{\mathbf{3}}\right)\end{array}$} & \multicolumn{2}{|c|}{$\begin{array}{l}\text { High Risk Energy Footprint } \\
\text { per capita }(\mathrm{MJ})\end{array}$} & \multicolumn{2}{|c|}{$\begin{array}{l}\text { High Risk Land Footprint } \\
\text { per capita (ha) }\end{array}$} \\
\hline 7539 & USA & 288,931 & USA & 2.03 & USA \\
\hline 2648 & Russia & 195,895 & SouthAfrica & 1.03 & Sudan \\
\hline 2355 & Ukraine & 192,331 & SouthKorea & 0.98 & Ukraine \\
\hline 2192 & Brazil & 173,049 & Japan & 0.95 & Russia \\
\hline 1969 & Argentina & 165,769 & France & 0.61 & France \\
\hline 1894 & Spain & 160,611 & Russia & 0.60 & Germany \\
\hline 1886 & France & 153,786 & UK & 0.57 & Brazil \\
\hline 1840 & Germany & 150,189 & Germany & 0.55 & Spain \\
\hline 1647 & Thailand & 126,187 & Spain & 0.48 & Japan \\
\hline 1576 & Italy & 118,963 & Italy & 0.47 & UK \\
\hline 1551 & Japan & 72,231 & Thailand & 0.46 & Thailand \\
\hline 1476 & UK & 71,501 & Ukraine & 0.44 & Argentina \\
\hline 1447 & Sudan & 67,103 & Turkey & 0.42 & Italy \\
\hline 1442 & SouthKorea & 66,015 & Argentina & 0.42 & Turkey \\
\hline 1397 & Colombia & 65,913 & Iran & 0.41 & China \\
\hline
\end{tabular}

Table 3 shows GDP-weighted water, energy and land footprints across major economies ${ }^{2}$. The high GDP-weighted water, energy and land footprints of India, China, and Russia suggest their economic development is a major driver of resource demand across the WEL system. Equivalent calculations for high risk resource use reveals other economies of importance; Turkey, India, Mexico, Spain and Italy in the case of high risk water use; South Korea, Indonesia, France, Spain, and Turkey in the case of high risk energy use; and, Brazil, USA, Canada, Mexico and France in the case of high risk land use.

Individual sectors exhibited a similar profile of water, energy and land risk to countries owing to the contribution of their production, consumption and trade dependencies to each country's overall demand. A small proportion of sectors exhibited low levels $(<10 \%)$ of exposure to high risk water use (9.9\%), high risk energy use $(12.3 \%)$ and high risk land use $(2.6 \%)$. However, in line with the country-level analysis, sectors were found to be more dependent on high risk land use than water or energy use and least exposed to high risk energy use of all three resource footprints analysed. Large within-country differences between sectors in terms of resource use and risk profile existed. These disparities imply scope for a triage-based approach to resource use analysis and management within countries.

\footnotetext{
${ }^{2}$ Major economies were defined as any country which contributes more than $1 \%$ to global GDP
} 
Table 3 GDP-weighted high-risk water, energy and land footprints among major economies

\begin{tabular}{llllll}
\hline $\begin{array}{l}\text { High Risk Water Footprint } \\
\text { per unit GDP }\left(\mathbf{m}^{\mathbf{3}} \mathbf{\$}\right)\end{array}$ & $\begin{array}{l}\text { High Risk Energy Footprint } \\
\text { per } \text { unit GDP }(\mathbf{T J} / \mathbf{\$})\end{array}$ & $\begin{array}{l}\text { High Risk Land Footprint } \\
\text { per unit GDP }(\mathbf{h a} / \mathbf{})\end{array}$ \\
\hline 0.50 & India & 12.3 & Russia & 164.3 & India \\
0.35 & Indonesia & 11.8 & India & 72.4 & Russia \\
0.21 & Brazil & 9.9 & China & 65.6 & China \\
0.20 & Russia & 9.9 & SouthKorea & 62.6 & Indonesia \\
0.14 & USA & 7.4 & Indonesia & 54.4 & Brazil \\
0.13 & Mexico & 6.3 & Turkey & 39.6 & Turkey \\
0.13 & Turkey & 5.5 & USA & 38.6 & USA \\
0.11 & China & 5.3 & Canada & 33.4 & Mexico \\
0.07 & SouthKorea & 5.1 & Mexico & 20.8 & Canada \\
0.07 & Canada & 4.8 & Brazil & 19.8 & Australia \\
0.06 & Spain & 4.4 & Australia & 19.5 & SouthKorea \\
0.05 & Australia & 4.2 & Japan & 17.0 & Spain \\
0.05 & France & 4.0 & France & 15.0 & Germany \\
0.05 & Germany & 3.9 & Spain & 14.8 & France \\
0.05 & Netherlands & 3.8 & Netherlands & 13.5 & Netherlands \\
\hline
\end{tabular}

\subsection{Domestic, macro-regional and remote dependencies across the WEL} system

This section highlights the importance of different spatial scales to the resource use and resource risk of countries and sectors modelled. In contrast to single (i.e. global) or two-tiered (i.e. domestic and non-domestic or domestic and macro-regional) assessments, country and sector resource use is evaluated at three spatial scales: domestically, macro-regionally, and remote (i.e. beyond the region a country is situated).

Countries and sectors are found to be highly dependent on non-domestic water, energy and land use. A significant number of countries are more dependent on water $(n=72)$, energy $(\mathrm{n}=81)$, and land use $(\mathrm{n}=81)$ abroad than in their own country. Many countries rely almost entirely $(>90 \%)$ on water $(n=29)$, energy $(n=52)$, and land $(n=45)$ resources in countries to satisfy their domestic demand for goods and services. Although the importance of nondomestic resource varies more greatly for sectors than countries, on average sectors exhibit a high dependence on water $($ median $=55.1 \%$, mean $=53.7 \%)$, energy $($ median $=36.4 \%$, mean $=43.5 \%)$, and land use $($ median $=80 \%$, mean $=65.7 \%)$ in countries other than their own. 
Although the borderless nature of national and sectoral resource use and resource risk is well documented ( $c f$ Bruckner et al., 2012; Chaudhary and Kastner, 2016; Krausmann et al., 2017; Lenzen et al., 2012; Taherzadeh et al., 2018; Wiedmann and Lenzen, 2018; Wood et al., 2014), the contribution of macro-regional and remote resource use to this remains poorly understood (Wiedmann and Lenzen, 2018). By further partitioning non-domestic resource fluxes embodied in national consumption and sectoral demand by macro-regional and remote sources such evaluation is possible. Figure 4 illustrates which of these scales (domestic, macro-regional or remote) account for the greatest proportion of national resource dependency and exposure to resource risk.

For many countries domestic water, energy and land use is greater than non-domestic macro-regional or remote resource use; this is illustrated by the yellow in Figure 4. Although macro-regional dependencies were not the most important factors for most countries, they still accounted for a modest proportion of overall national water use (median $=3.9 \%$, mean $=7.4 \%)$, energy use $($ median $=5.5 \%$, mean $=9.9 \%)$ and land use $($ median $=3.9 \%, 8.4 \%)$. The importance of national resource use to national resource footprints does not imply national self-sufficiency in water, energy and land use for countries, but simply indicates national borders are an important unit of resource use assessment and management.

Moreover, for several countries, remote production accounts for the greatest source of their total water use (Canada, Chile, South Sudan), energy use (Botswana, Laos, Luxembourg, MacaoSAR, Namibia, and Swaziland) and land use (Chile, Côte d'Ivoire, New Zealand and Zimbabwe) footprint. International trade also represents the greatest source of national exposure to risks across the WEL system, as shown by the importance of remote and - to a lesser degree - macro-regional, production sources to countries' water, energy and land risks in Figure 4 (right hand maps). 


\section{Boundaries of national resource footprints}

\section{Boundaries of national resource risk}
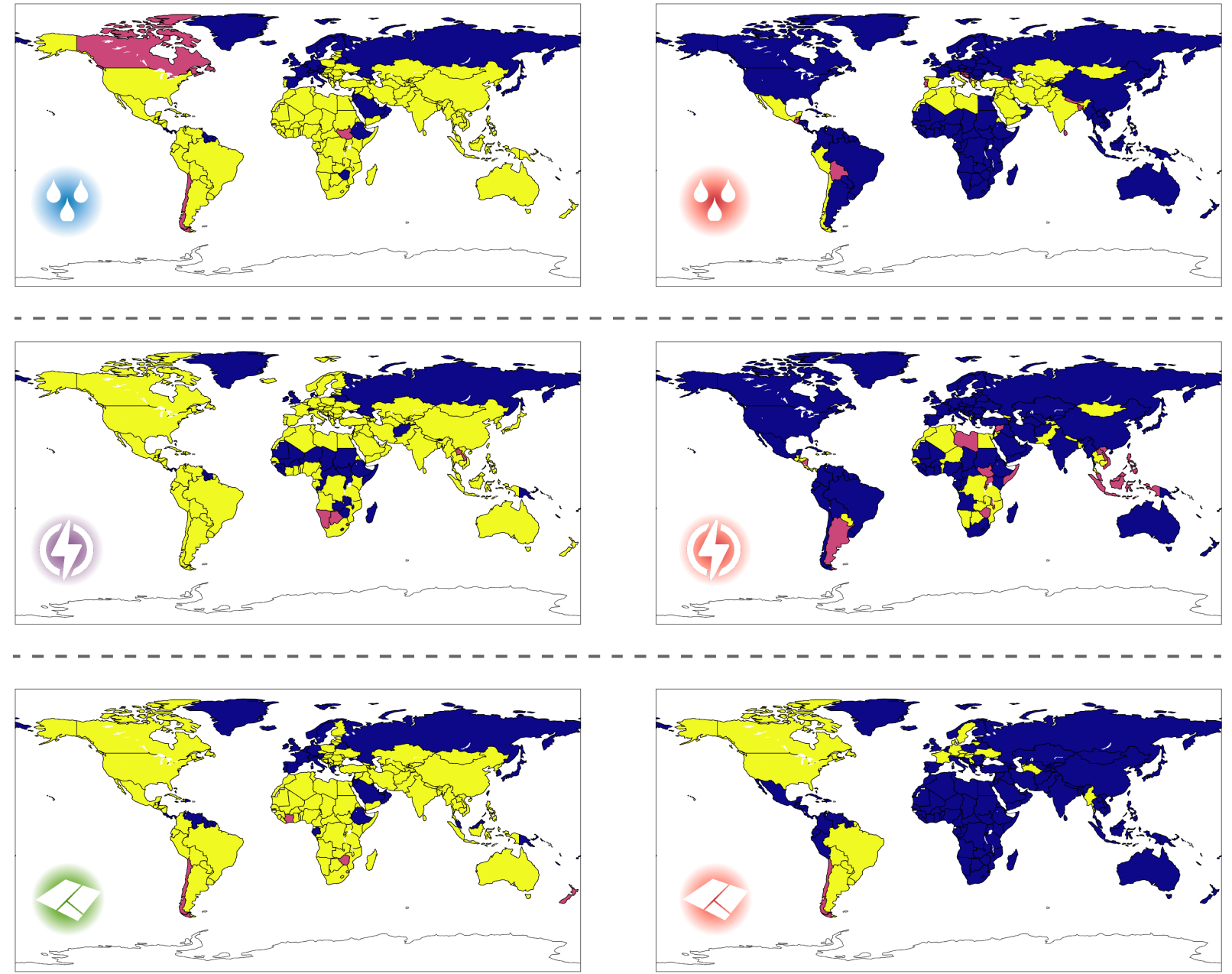

Critical boundaries for country resource footprints and resource risk

Figure 4 Major sources of country resource supply and risk across the WEL system Chloropleth maps with shading of countries according to their most important resource origin (domestic $=$ yellow; macro-regional $=$ pink; remote $=$ blue $)$ on water, energy and land use. Left hand figures relate to important boundaries of overall national resource footprints. Right hand figures relate to important boundaries of national high risk resource dependence. 
International trade is associated with $19.8 \%, 30.5 \%$ and $22.5 \%$ of high risk water, energy and land use respectively. For most countries international trade is (i) a greater source of water risk $(n=159)$, energy risk $(n=153)$ and land risk $(n=172)$ than domestic production and (ii) the only source of national exposure to water risk $(n=150)$, energy risk $(n=150)$, and land risk $(\mathrm{n}=166)$. The relative importance of non-domestic resource dependency for a given country is a product of its domestic resource risk, domestic self-sufficiency and the resource risk associated within its major trading partners. To this end, it is possible for a country to exhibit the greatest exposure to resource risk from remote sources, because of the relatively low risk associated with both its own domestic resource use, and the resource use in its neighbouring countries. Equally, countries can be more highly exposed to high risk resource use domestically if their own resource risk is classified as 'high risk' and their virtual import of high-risk resource use through trade is lower than their internal resource footprint. Figure 5 shows the major role international trade plays as a conduit of sectoral resource use and risk across the WEL system. Since this analysis covers many thousands of sectors, Figure 5 is designed to convey general trends in the resource origins of sectoral resource use and risk. The radial axis used allows such an aggregated view by creating a 'fan' comprising the levels of non-domestic domestic resource use and risk in each sector, the spread of which indicates the importance of international trade across the world economy. 


\section{Sectoral Water Footprints}

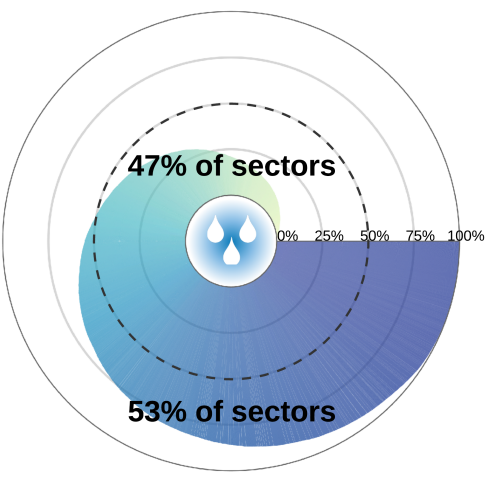

Sectoral Water Risk

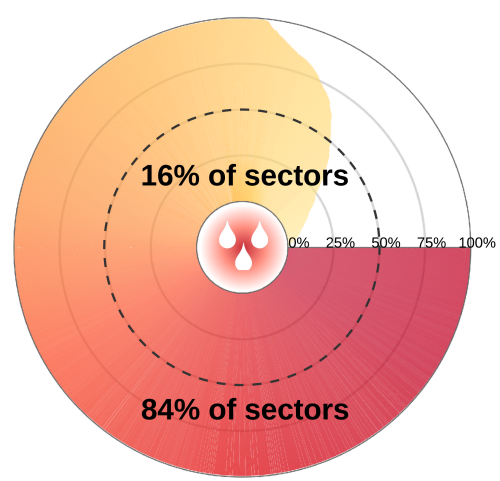

\section{Sectoral Energy Footprints}

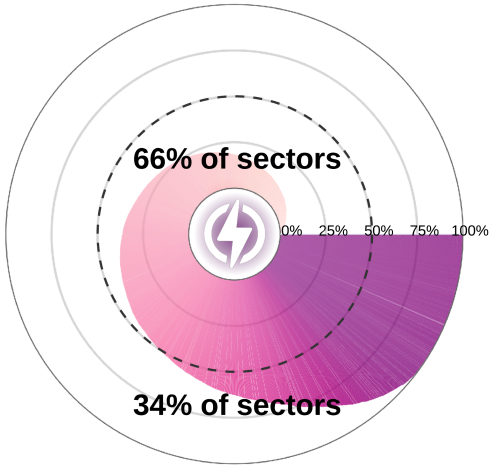

Sectoral Energy Risk

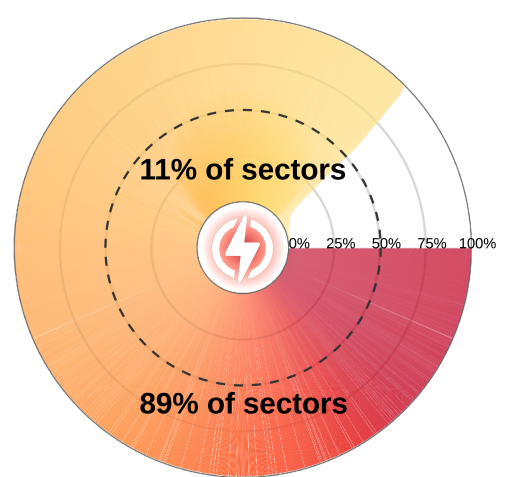

\section{Sectoral Land Footprints}

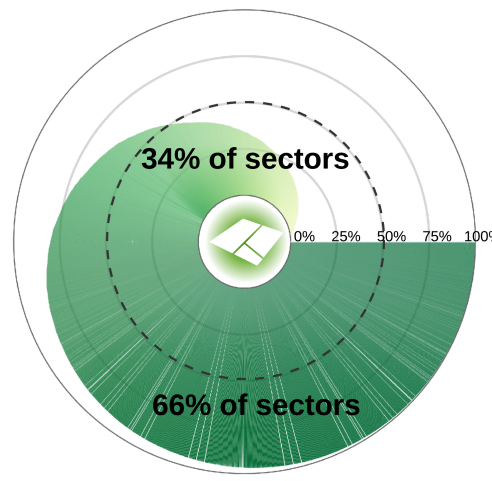

Sectoral Land Risk

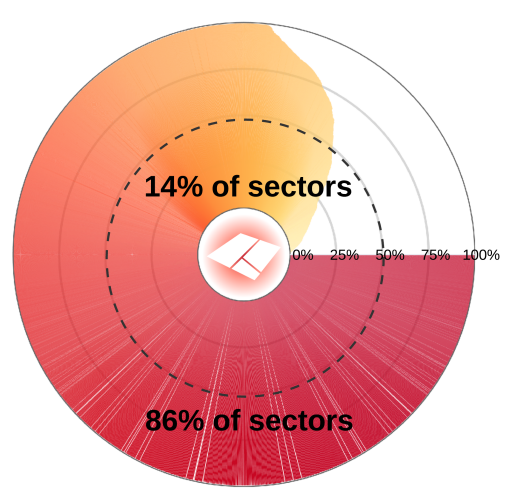

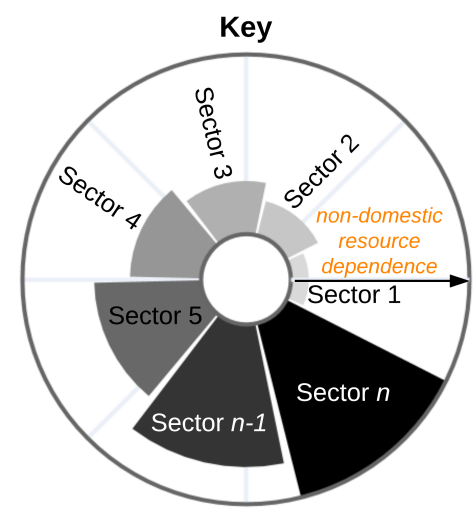

Figure 5 Plot of the contribution of trade to sectoral resource use and to high risk resource use

Circular radar graphs displaying the contribution (\%) of non-domestic resources (i.e. international trade) to a sector's overall water, energy and land use (top) and high-risk water, energy and land use (bottom). Dashed line delineates the proportion of sectors which exhibit greater reliance on domestic (inside) or non-domestic (outside) resource use or resource risk. 

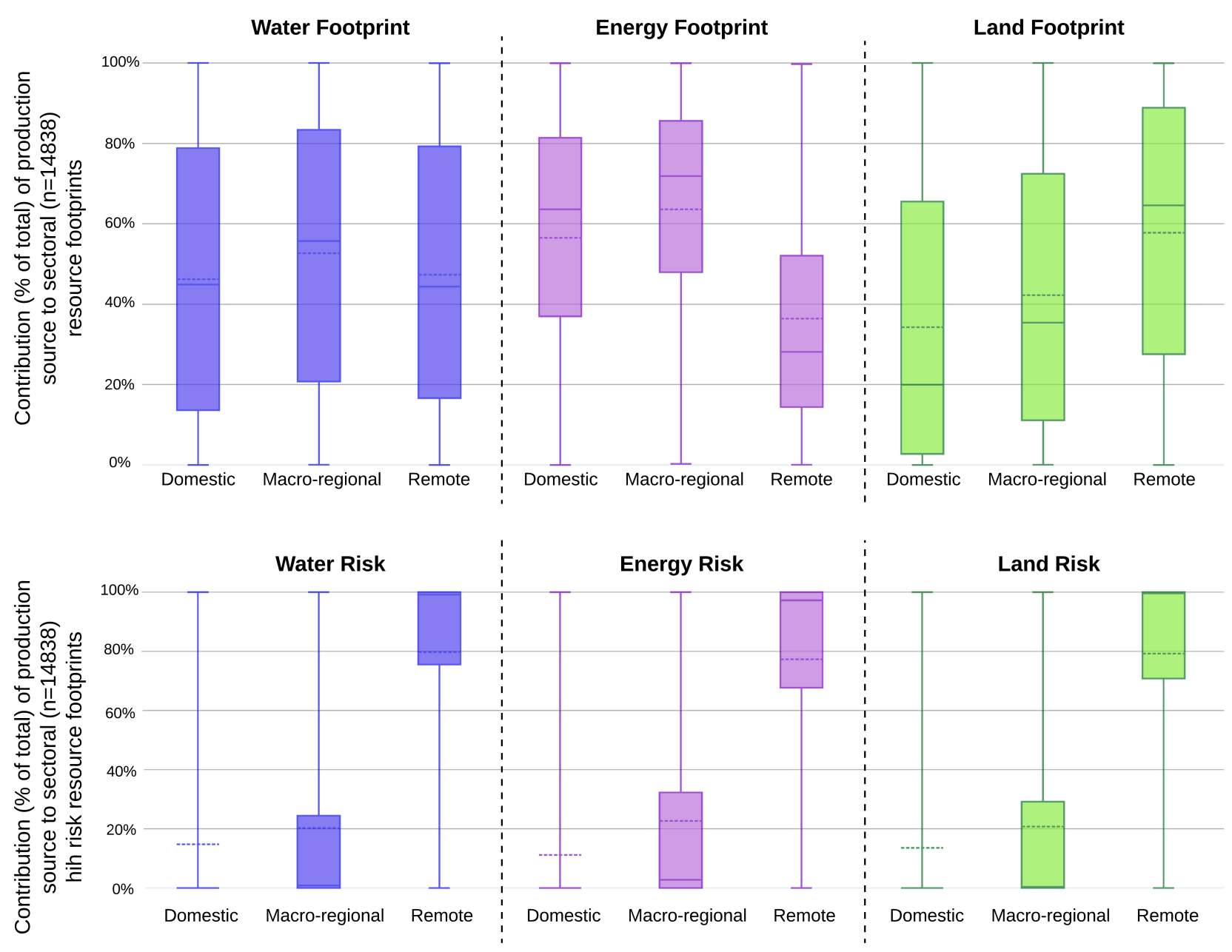

Figure 6 Trade and the WEL footprint of sectors

Box plots showing the contribution of domestic, macro-regional and remote production sources to overall sectoral water, energy and land use (top) and high-risk sectoral water, energy and land use 
The apparent mismatch between spatial scales of national resource dependency and resource risk exposure are of major consequence to resource use assessment in individual countries and globally. Argentina exemplifies this heterogeneity with its most important scales of national exposure to water risk (remote), energy risk (macro-regional) and land risk (domestic) being entirely misaligned. According to our assessment there are no countries for which truncation of WEL system assessment to a national-level or a macro-regional level would capture the most significant source of water, energy and land risk simultaneously.

Ostensibly, the globalised nature of the country and sector interactions across the WEL system implies no obvious entry point to mitigate country and sectoral resource pressures and risks. However, cross-cutting analysis of national and sectoral resource origins across the WEL system, summarised in Figure 7, reveals specific regions and countries which exert major influence across this system. To this end, many countries and sectors share the same source of resource supply and risk (Figure 7). For all 189 countries analysed, India was one of the greatest sources of national high risk water, followed by Pakistan, Spain and Italy. Thailand is the most common source of national energy risk, a finding supported by other similar studies (see GEI, 2018; Kamsamrong and Sorapipatana, 2014; Vivoda, 2010), followed by Algeria and Ethiopia. The USA, Argentina and Brazil were the top ten sources of land risk. Meanwhile, common sources of national water, energy and land risk also featured among the top sources of sectoral risk, as shown by comparing Figures 6 and 7. In terms of overall water, energy and land use, the USA, China and Algeria were among the top sources of sectoral resource use (Figure 7). The primacy of Algeria to sectoral water, energy and land use is likely explained by its exports of i) oil and gas reserves (in the case of energy), (ii) agricultural commodities produced with low water efficiency and a high ratio of blue to green water (in the case of water) (Jacobs and van Klooster, 2012), and extensive, inefficient land use (in the case of land) (Houyou et al., 2016). The immediate policy implication of the identification of resource risk hot-spots is to divert national procurement away from high risk resource use in key sectors, namely, the food sector in the case of water and land risk and energy-intensive sectors (e.g. construction, transport and infrastructure) in the case of energy risk. However, since such measures might be regressive in nature and difficult to implement in practice, policies to reduce international inequalities and fragility in resource insecure nations should also be explored alongside this. These supply-side measures could involve debt cancellation, investment in resource efficiencies in key sectors, and promotion of equitable and sustainable terms of trade between nations. 


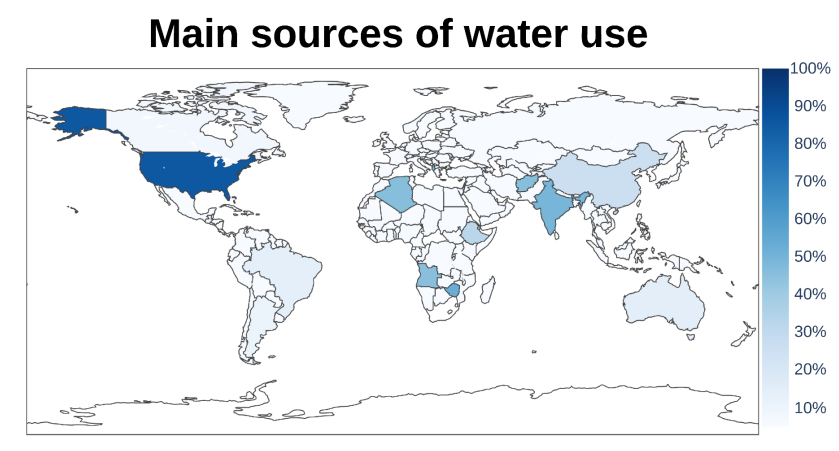

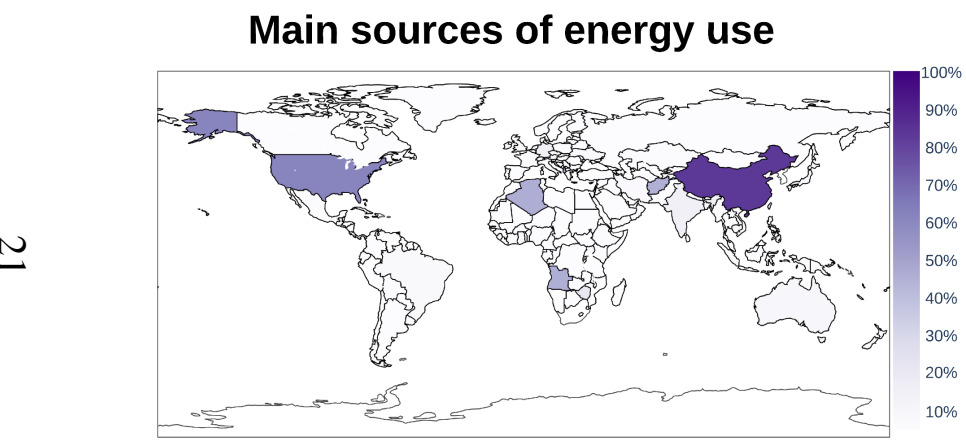

Main sources of land use

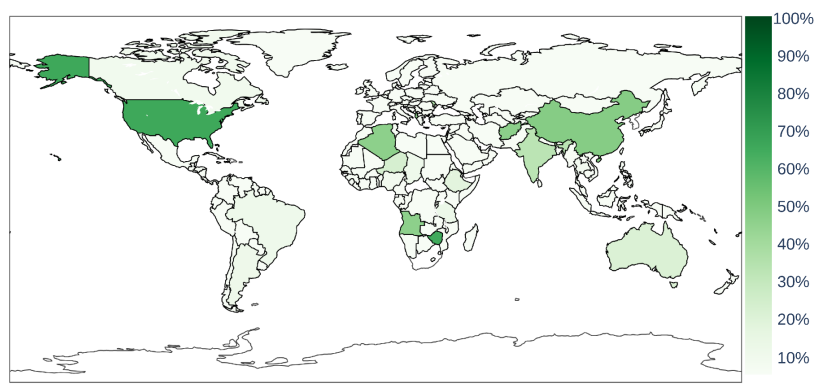

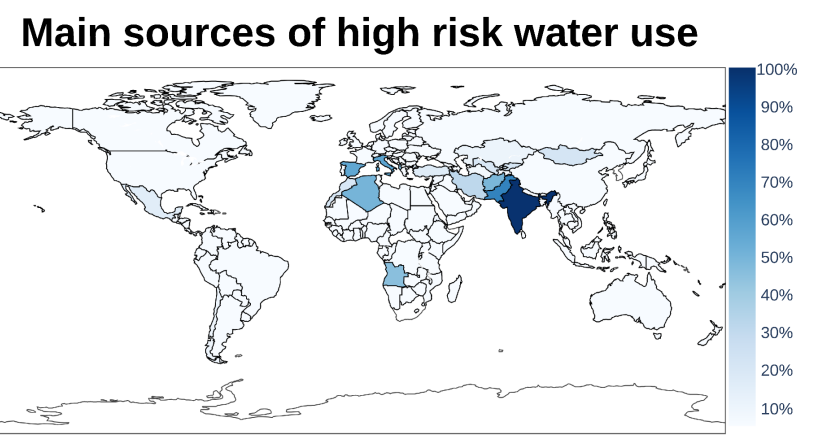

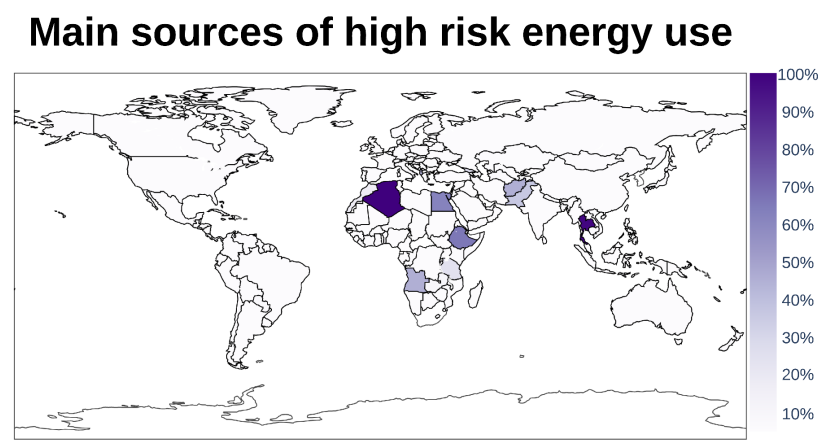

\section{Main sources of high risk land use}

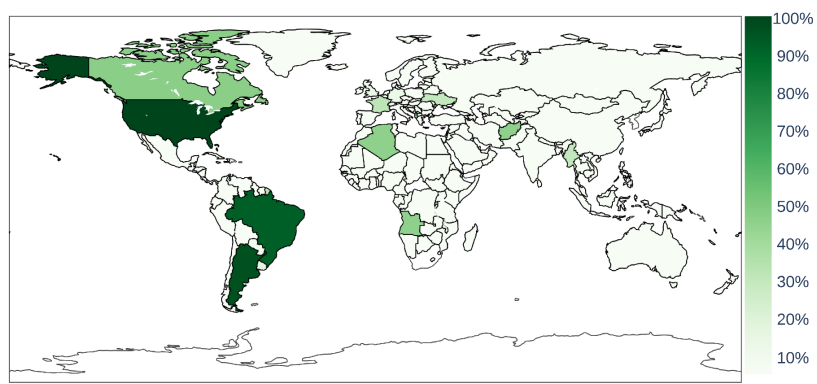

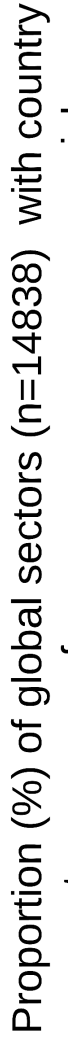

Figure 7 Main sources of resource use and resource risk

Choropleth maps with shading of countries according to their frequency of appearance in the top 10 sources of sectoral resource dependence (left) or high risk sectoral resource dependence (right) 


\subsection{Linking local resource insecurity to macro-economic flows}

The availability of, and access to, natural resources varies greatly within countries. Accordingly, the resource insecurity of national production, consumption, and international trade is determined by the sustainability of resource use at a sub-national level (Godar et al., 2015). The uniform treatment of national resource use as either low, medium or high risk ignores these sub-national differences and their combined influence on the resource insecurity of domestic production and trade pathways (Lenzen et al., 2013a). In large countries, where resource security exhibits large internal variation, integrating sub-national resource use and risk data into macroeconomic assessment of resource insecurity is potentially valuable (Guan and Hubacek, 2007).

Recent scholarship has sought to link local resource use explicitly to macro-economic flows by constructing sub-national MRIO frameworks. This has enabled exposure of differences in the source and severity of risk to national resource footprints in Australia (Lenzen, 2009), Brazil (Veiga et al., 2018), China (Wang et al., 2012), the USA (Faturay et al., 2020) and other major economic centres (Faturay et al., 2020). However, the lack of sub-national production, consumption and trade data at the global, multi-country scope of this study prevents a meaningful linkage of local resource insecurity to macro-economic flows. Nevertheless, a partial integration of localised resource insecurity into the global framework of this study is possible by linkage of sub-national resource use and risk data, where the data exists. This is demonstrated for national water footprint by weighting national water flows by sub-regional water extraction and risk data. We integrate sub-national resolution resource use and risk data from the WRI Aqueduct database, reported in Hofste et al. (2019), for Australia (11 regions), China (132 regions), India (137 regions) and the United States (246 regions), extending the overall resolution of analysis from 189 regions (i.e. countries) to 707 regions. The resultant model (hereafter "weighted model") identifies the variability of water use risk in each of these four countries from the relative volume and risk of water use in their sub-regions, instead of using a nationally averaged total as in the preceding analysis (hereafter "basic model"). 


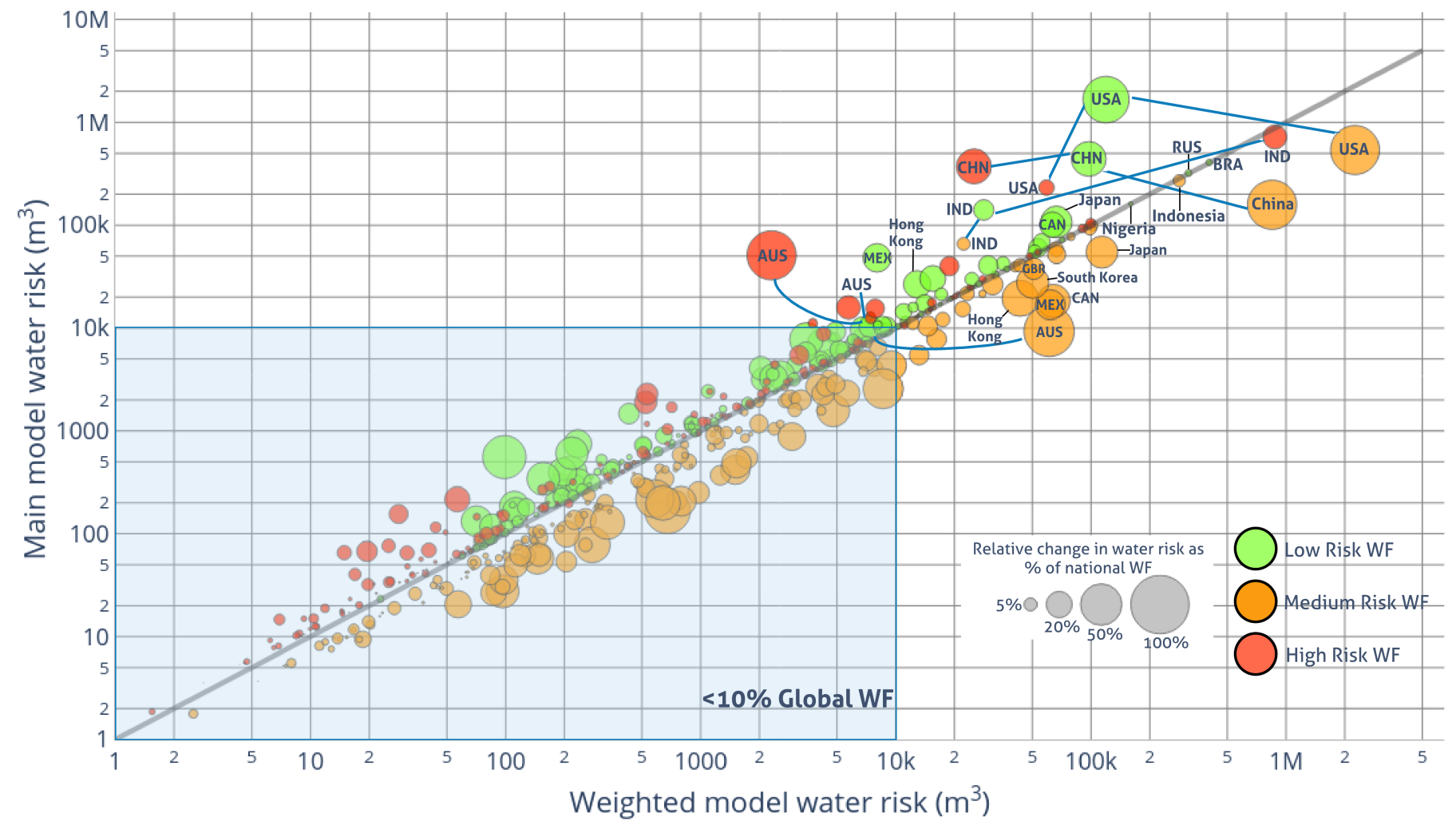

Figure 8 Effects of sub-national water risk data on national water risk assessment

Differences in low, medium and high risk water use embodied in national consumption between the basic model used in this study and a weighted model integrating sub-national water use and risk data for Australia, China, India and the United States. Changes to the water risk profile of these countries are highlighted along with other key countries. Line of equality represents equivalence between values from the basic model and weighted model. Full results can be found in the online supplementary material. 
The weighted model estimates different levels of water-related risk within the four aforementioned countries, as well as their major trading partners, which includes most of the remaining 185 countries. The deviations of national-level water risk arising between the main and weighted model in each of the risk categories are shown in Figure 8. Changes were most acute in the four countries where macro-regional level water risk weightings were used.

In Australia, an increased proportion (from $3.4 \%$ to $74.4 \%$ ) of its water footprint is characterised by high risk whilst a lower proportion (from $89 \%$ to $13.6 \%$ ) is medium risk. In China, a similar fall is observed in relation to its medium risk water use (decreasing from $87.3 \%$ to $16.3 \%$ ), which is compensated by increases in both its low risk water use (from $10 \%$ to $45.2 \%$ ) and high risk water use (from $2.6 \%$ to $38.4 \%$ ). In contrast, following the integration of weighted water use and risk data, the proportion of India's water footprint classified as high risk fell moderately (from $90.1 \%$ to $74 \%$ ) and its medium risk water use rose (from $2.9 \%$ to $14.5 \%$ ). Water use in the USA is also re-classified from mainly medium risk (92.6\%) to low risk (68.3\%), although an increase (from $2.4 \%$ to $9.5 \%$ ) is also observed in its high risk water use. These changes collectively affect and are affected by the risk associated with water use embodied in international trade flows, as shown in Figure 8, by the changing water risk portfolio of Mexico, Canada, Japan and South Korea. The net effect of the weighted model implies a reduction in the relative proportion of medium risk water use, but an increase in high risk and low risk water use associated with national consumption.

Weighting resource use and risk data for major countries also has a large effect on the proportion of low, medium and high risk associated with water use at a global level since the four countries whose resource use and risk data were integrated account for $46.5 \%$ of global water use and $24 \%$ of global virtual water use. Consequently, we observe a near doubling of the proportion of low risk global water use (from $26.7 \%$ to $50.9 \%$ ), halving of medium risk water use (from $51.8 \%$ to $22.2 \%$ ), and slight increase (21.1\% to $26.4 \%$ ) of high risk water use. The water risk profile of international trade flows shows a similar trend. However, in line with the basic model, countries still exhibit greater exposure to high risk water use from trade than domestic production.

The results of this abridged analysis, summarised in full in the supplementary data, illustrates how sub-national resource use and risk data can be used to better evaluate the resource insecurity in both individual countries and globally. However, the results of this model must be interpreted with care since it contains several assumptions from the basic model, discussed in Section 4. Moreover, the weighted model assumes all countries depend 
on the same sources of resource extraction implied by the sub-national resource use and risk data. However, recent studies suggest that countries invariably rely on different sources of production to satisfy their own demand and exports, resulting in a plethora of different resource use and risk pathways (Moran et al., 2020). Moreover, differences in the temporal range and underlying methodology of the water risk data used in the basic model and the weighted model prevent a full evaluation of the effect(s) of down-scaling our study.

Without a global-scale, sub-national resolution MRIO, the exact resource dependencies and risk exposure of countries is difficult to quantify accurately. Nonetheless, the analysis from the basic model and weighted model are instructive when viewed within the context of existing scholarship. Whilst equivalent sub-regional down-scaling of the analysis for energy and land was not possible due to the lack of the necessary sub-national resource use and risk data, this assessment for water offers a methodological framework for use as more detailed data becomes available.

\section{Discussion}

The production and consumption of goods and services link economic actors in complex and globalised supply chains. As a result, the environmental burden of countries and sectors is distributed across various production locations worldwide. Where this resource demand is imposed matters to the effective management of the water-energy-land (WEL) system. However, to date resource use studies have been truncated, spatially and sectorally, which prevents a systematic overview of resource pressures and their source. This study develops and demonstrates a flexible approach to examining pressures across the WEL system at various spatial and sectoral scales. This framework provides several improvements when compared to existing methods of resource use assessment. Undertaking resource use assessment using MRIOA enables a self-consistent cross-comparison of country and sector resource pressures across the WEL system. This systematic overview of the WEL system lends itself to the identification of key priorities (countries, macro-regions and sectors) to improve the sustainability of natural resource use in individual countries and globally. The data-driven nature of MRIOA, when used in combination with large environmental datasets, enables rapid development of resource use case studies for a vast number of country (189) 
and sectors (14838) which would be prohibitively complex and slow based on a case study approach (Vivanco et al., 2018a).

By linking country and sector resource use to source, this study makes several contributions to natural resource accounting scholarship. Foremost, this assessment develops a foundational understanding of country and sector resource interdependencies across the water-energy-land system at national, macro-regional and remote scales. This multi-scale analysis reveals resource pressures and resource risks are often remote to the locations of national and sectoral consumption. This finding has major implications for the study and management of the WEL system. Namely, it highlights the need for global-level assessment of country and sector pressures and policy priorities across the WEL system which is rarely undertaken at present. This also suggests that analysts and decision makers would benefit from exercising caution when truncating resource use assessment to national or macroregional levels since such units of analysis are likely to ignore large, and potentially more significant, resource use and resource use risk driven by countries and sectors via remote international trade flows. Indeed, we show how most countries exhibit greater exposure to resource risks via international trade $(\approx 80-90 \%)$, mainly from remote production sources. However, the factors underlying such trends require further analysis in order to identify suitable management interventions in each of the countries analysed. Levelling such an assessment at the resource endowments, comparative advantage and trade policies between countries would be a useful line of inquiry towards this end.

Despite the complex and globalised nature of resource use pathways within the global economy, countries and sectors depend on and are exposed to common sources of resource supply and high risk resource use. This implies that simply diversifying trading partners, is unlikely to help countries and sectors improve their resource self-sufficiency or exposure to resource risks. Accordingly, focusing on resource risk reduction at source appears necessary to promote more sustainable management of water, energy, and land resources, in individual countries and globally. Moreover, within the context of national resource security, reducing dependence on non-domestic resource supply sources, may help to improve the resilience of countries to supply chain shocks related to resource mismanagement upstream in global supply chains.

In addition to its application to resource use assessment and management, this study contributes towards several other avenues of research and policy inquiry. First, this assessment provides a global and cross-sectoral assessment how water, energy and land risks connect 
different actors within the global economy, enabling comparison of resource insecurities within and between countries and sectors which have not previously been studied. Second, this detailed decomposition of global water, energy and land use provides a framework and dataset to help operationalise the assessment of risks across their respective planetary boundaries at a national and sectoral level, helping to contextualise existing assessments of sustainability consumption ( $c f$ Fang et al., 2015b; Hoekstra and Wiedmann, 2014; O'Neill et al., 2018). Lastly, this analysis reveals how and where countries outsource water, energy and land risk through their various consumption activities, adding to the body of evidence concerning carbon leakage, virtual resource trade and pollution havens (Bruckner et al., 2012; López et al., 2018; Xu et al., 2019)

These findings must be viewed within the constraints of available data and modelling techniques. First, the availability of, and access to, natural resources varies spatially and sectorally. This heterogeneity is not captured by using national-level data. Although subnational resource risk datasets exist for water use (Hoekstra et al., 2012), energy use (BEIS, 2018), and land use (Croft et al., 2018), the absence of detailed sub-national macroeconomic (production, consumption and trade) data precludes analysis of country and sector (riskbased) resource footprints at a higher resolution (Hubacek and Feng, 2016; Otto et al., 2015). Second, grouping country production sources and resource footprints by three risk categories does not fully reflect the severity of risk associated with production sources underpinning national and sectoral consumption. Nevertheless, this ranking offers a reasonable proxy which can be communicated in an accessible and actionable way. Third, the risk indices themselves also introduce uncertainty to this assessment. Risk indices are based on data and modelled outputs which are subject to deficiencies, and their relationship to the actual consequences of national exposure to the production sources they measure is potentially complex. This limitation is most pertinent to composite indicators, such as the energy risk indicator used, which conflates political and environmental threats. Fourth, there is a strong positive, and likely causal, relationship between the severity of country's domestic resource risks and a country's exports. However, it is difficult to unpick an exact cause-effect relationship between domestic resource risk and trade in the absence of time-series data on national resource risks. Accordingly, additional research is needed to distinguish the influence of domestic production and exports on national resource risk. Fifth, there are known inadequacies of MRIO databases and national environmental accounts which could not feasibly be resolved within this study. These mainly concern: the use of financial data 
instead of physical data to approximate the weight and direction of resource fluxes across global supply chains (Hubacek and Feng, 2016); misreporting and miscalculation of national economic and environmental accounts (Timmer et al., 2015); and, procedures used to ensure input-output tables balance (Lenzen et al., 2013b).

The macro scale at which this analysis has been undertaken, given the data available, does not map directly onto a set of effective actors or scales of management. In practice, the level of coordination, power sharing and information exchange which would be necessary for the management of global value chains varies at the scale of individual businesses and their supply chains (Emmett and Crocker, 2006). Consequently, the ability of national governments or even sectors to identify, engage with, and regulate suppliers, and to codify sustainable production practices effectively is limited without collective effort (Gereffi et al., 2005). Indeed, suppliers are governed by both public and private authority at multiple scales and levels, and under multilateral and normative objectives. This multi-polar nature of supply chain governance, combined with the complex and fragmented organisation of suppliers, creates no obvious entry point for the management of pressures within the WEL system. Whilst sophisticated quantitative analysis can help to identify focal points (i.e. sub-systems) of the WEL system which exert a major influence on the demand for natural resources, its relationship to problem framing and knowledge production in natural resource management should be held in simultaneous view with other perspectives, both quantitative and qualitative, when studying challenges across the WEL system. This study offers one perspective to derisking the WEL system. By exposing differences between the scale and severity of risk associated with country and sector resource footprints, the analysis in this study can help to redress notions of responsibility and inequity within this context. However, an analysis of the political economy of global value chains is necessary to unpack fully the challenge of achieving sustainable systems of production and consumption (Heron et al., 2018). The absence of this perspective is symptomatic of wider scholarship on the WEL system which has been dominated by quantitative lines of inquiry with few practical recommendations for its governance (Stirling, 2015). However, we hope our study can identify key areas for future policy analysis.

Although limited by the quality of existing data, the flexibility of this assessment framework is capable of accommodating higher resolution sub-national (e.g. national regions and municipalities) and sectoral (i.e. commodity and company) assessment, different environmental risk parameters, and expanding definitions of the 'nexus' (e.g. climate, minerals, 
749 and/or ecosystems), as new datasets and methods for resource footprinting emerge. Such 750 an adaptive research approach is needed to respond to the complex and constantly evolving 751 questions surrounding global environmental challenges. 



\section{r2 Bibliography}

Albrecht, T. R., Crootof, A., and Scott, C. A. (2018). The Water-Energy-Food Nexus: A systematic review of methods for nexus assessment. Environmental Research Letters, 13(4):043002.

Allan, J. A. (2003). Virtual Water - the Water, Food, and Trade Nexus. Useful Concept or Misleading Metaphor? Water International, 28(1):106-113.

Allan, J. A. (2010). The Middle East water question: hydropolitics and the global economy. Tauris, London, reprinted edition. OCLC: 837920961.

Allouche, J., Middleton, M., and Gyawali, D. (2015). Technical Veil, Hidden Politics: Interrogating the Power Linkages behind the Nexus. Water Alternatives, 8(1):610-626.

Alting, D. L. and Jøgensen, D. J. (1993). The Life Cycle Concept as a Basis for Sustainable Industrial Production. CIRP Annals, 42(1):163-167.

Andrews-Speed, P., Bleischwitz, R., Boersma, T., Johnson, C., Kemp, G., and VanDeveer, S. (2012). The Global Resource Nexus: The Struggles for Land, Energy, Food, Water, and Minerals. Technical report, Transatlantic Academy, Washington, D.C., United States.

Ayres, R. U., Ayres, L. W., and Martinás, K. (1998). Exergy, waste accounting, and life-cycle analysis. Energy, 23(5):355-363.

Behzadi, G., O’Sullivan, M. J., Olsen, T. L., and Zhang, A. (2018). Agribusiness supply chain risk management: A review of quantitative decision models. Omega, 79:21-42.

BEIS (2018). Sub-national electricity and gas consumption statistics. Regional and Local Authority. Technical report.

Bijl, D. L., Bogaart, P. W., Dekker, S. C., and van Vuuren, D. P. (2018). Unpacking the nexus: Different spatial scales for water, food and energy. Global Environmental Change, 48:22-31.

Bringezu, S., Schütz, H., and Moll, S. (2003). Rationale for and Interpretation of EconomyWide Materials Flow Analysis and Derived Indicators. Journal of Industrial Ecology, 7(2):43-64. 
Bruckner, M., Fischer, G., Tramberend, S., and Giljum, S. (2015). Measuring telecouplings in the global land system: A review and comparative evaluation of land footprint accounting methods. Ecological Economics, 114:11-21.

Bruckner, M., Giljum, S., Lutz, C., and Wiebe, K. S. (2012). Materials embodied in international trade - Global material extraction and consumption between 1995 and 2005. Global Environmental Change, 22(3):568-576.

Cai, B., Zhang, W., Hubacek, K., Feng, K., Li, Z., Liu, Y., and Liu, Y. (2019). Drivers of virtual water flows on regional water scarcity in China. Journal of Cleaner Production, 207:1112-1122.

Carmona-Moreno, C., Dondeyanaz, C., and Biedler, M. (2019). Position paper on water, energy, food and ecosystems (wefe) nexus and sustainable development goals (SDGs). Technical Report EUR 29509 EN, European Union.

Chaudhary, A. and Kastner, T. (2016). Land use biodiversity impacts embodied in international food trade. Global Environmental Change, 38:195-204.

Chen, G. Q. and Han, M. Y. (2015). Global supply chain of arable land use: Production-based and consumption-based trade imbalance. Land Use Policy, 49:118-130.

Cherp, A. and Jewell, J. (2014). The concept of energy security: Beyond the four As. Energy Policy, 75:415-421.

Cook, C. and Bakker, K. (2012). Water security: Debating an emerging paradigm. Global Environmental Change, 22(1):94-102.

Council, W. E. (2018). World Energy Trilemma Index 2018. Technical report.

Croft, S. A., West, C. D., and Green, J. M. H. (2018). Capturing the heterogeneity of sub-national production in global trade flows. Journal of Cleaner Production, 203:11061118.

Daher, B. T. and Mohtar, R. H. (2015). Water-energy-food (WEF) Nexus Tool 2.0: guiding integrative resource planning and decision-making. Water International, 40(5-6):748771.

Dalin, C., Wada, Y., Kastner, T., and Puma, M. J. (2017). Groundwater depletion embedded in international food trade. Nature, 543(7647):700-704.

Dao, H., Peduzzi, P., and Friot, D. (2018). National environmental limits and footprints based on the Planetary Boundaries framework: The case of Switzerland. Global Environmental Change, 52:49-57.

Davis, S. J. and Caldeira, K. (2010). Consumption-based accounting of CO2 emissions. Proceedings of the National Academy of Sciences, 107(12):5687-5692. 
Dietzenbacher, E., Lenzen, M., Los, B., Guan, D., Lahr, M. L., Sancho, F., Suh, S., and Yang, C. (2013). Input-Output Analysis: The Next 25 Years. Economic Systems Research, 25(4):369-389.

Duan, C. and Chen, B. (2017). Energy-water nexus of international energy trade of China. Applied Energy, 194:725-734.

Duro, J. A., Lauk, C., Kastner, T., Erb, K.-H., and Haberl, H. (2020). Global inequalities in food consumption, cropland demand and land-use efficiency: A decomposition analysis. Global Environmental Change, 64:102124.

Elgert, L. (2016). 'More soy on fewer farms' in Paraguay: challenging neoliberal agriculture's claims to sustainability. The Journal of Peasant Studies, 43(2):537-561.

Emmett, S. and Crocker, B. (2006). The relationship-driven supply chain: creating a culture of collaboration throughout the chain. Gower, Aldershot, Hampshire, England ; Burlington, VT.

Endo, A., Tsurita, I., Burnett, K., and Orencio, P. M. (2015). A review of the current state of research on the water, energy, and food nexus. Journal of Hydrology: Regional Studies.

Eora (2019). Eora Global MRIO.

Erb, K.-H., Haberl, H., DeFries, R., Ellis, E. C., Krausmann, F., and Verburg, P. H. (2012). Pushing the Planetary Boundaries. Science, 338(6113):1419-1420.

Eurostat (2020). eurostat.

Fang, K., Heijungs, R., and de Snoo, G. R. (2014). Theoretical exploration for the combination of the ecological, energy, carbon, and water footprints: Overview of a footprint family. Ecological Indicators, 36:508-518.

Fang, K., Heijungs, R., and De Snoo, G. R. (2015a). Understanding the complementary linkages between environmental footprints and planetary boundaries in a footprint-boundary environmental sustainability assessment framework. Ecological Economics, 114:218226.

Fang, K., Heijungs, R., Duan, Z., and de Snoo, G. R. (2015b). The Environmental Sustainability of Nations: Benchmarking the Carbon, Water and Land Footprints against Allocated Planetary Boundaries. Sustainability, 7(8):11285-11305.

FAO, editor (2011). The state of the world's land and water resources for food and agriculture: managing systems at risk. Earthscan, Milton Park, Abingdon ; New York, NY, 1st ed edition. OCLC: ocn746315976.

FAO (2015). MOSAICC: A modelling system for the assessment of the agricultural impacts of climate change. Technical report, Food and Agriculture Organization of the United Nations, Rome, Italy. 
FAO (2019). FAOSTAT. Technical report.

FAO (2020). Aquastat.

Faturay, F., Vunnava, V. S. G., Lenzen, M., and Singh, S. (2020). Using a new USA multiregion input output (MRIO) model for assessing economic and energy impacts of wind energy expansion in USA. Applied Energy, 261:114141.

Fayezi, S., O'Loughlin, A., and Zutshi, A. (2012). Agency theory and supply chain management: a structured literature review. Supply Chain Management: An International Journal.

Flörke, M., Kynast, E., Bärlund, I., Eisner, S., Wimmer, F., and Alcamo, J. (2013). Domestic and industrial water uses of the past 60 years as a mirror of socio-economic development: A global simulation study. Global Environmental Change, 23(1):144-156.

Folke, C. (2016). Resilience (Republished). Ecology and Society, 21(4).

Freire-González, J. (2019). Does Water Efficiency Reduce Water Consumption? The Economy-Wide Water Rebound Effect. Water Resources Management, 33(6):21912202.

Friday, D., Ryan, S., Sridharan, R., and Collins, D. (2018). Collaborative risk management: a systematic literature review. International Journal of Physical Distribution \& Logistics Management.

Galli, A., Wiedmann, T., Ercin, E., Knoblauch, D., Ewing, B., and Giljum, S. (2012). Integrating Ecological, Carbon and Water footprint into a "Footprint Family" of indicators: Definition and role in tracking human pressure on the planet. Ecological Indicators, 16:100-112.

GEI (2018). International index of energy security risk: assessing risk in a global energy market. Global Energy Institute (U.S. Chamber of Commerce), Washington D.C., United States.

Gereffi, G., Humphrey, J., and Sturgeon, T. (2005). The governance of global value chains. Review of International Political Economy, 12(1):78-104.

Giampietro, M., editor (2014). Resource accounting for sustainability assessment: the nexus between energy, food, water and land use. Routledge explorations in sustainability and governance. Routledge, Taylor \& Group, London : New York.

Gleick, P. H. and Heberger, M. (2014). Water and Conflict. In Gleick, P. H., editor, The World's Water: The Biennial Report on Freshwater Resources, pages 159-171. Island Press/Center for Resource Economics, Washington, DC. bibtex: gleick_water_2014.

Godar, J., Persson, U. M., Tizado, E. J., and Meyfroidt, P. (2015). Towards more accurate and policy relevant footprint analyses: Tracing fine-scale socio-environmental impacts of production to consumption. Ecological Economics, 112:25-35. 
Govindan, K., Azevedo, S. G., Carvalho, H., and Cruz-Machado, V. (2014). Impact of supply chain management practices on sustainability. Journal of Cleaner Production, $85: 212-225$.

Green, J. M. H., Cranston, G. R., Sutherland, W. J., Tranter, H. R., Bell, S. J., Benton, T. G., Blixt, E., Bowe, C., Broadley, S., Brown, A., Brown, C., Burns, N., Butler, D., Collins, H., Crowley, H., DeKoszmovszky, J., Firbank, L. G., Fulford, B., Gardner, T. A., Hails, R. S., Halvorson, S., Jack, M., Kerrison, B., Koh, L. S. C., Lang, S. C., McKenzie, E. J., Monsivais, P., O’Riordan, T., Osborn, J., Oswald, S., Price Thomas, E., Raffaelli, D., Reyers, B., Srai, J. S., Strassburg, B. B. N., Webster, D., Welters, R., Whiteman, G., Wilsdon, J., and Vira, B. (2016). Research priorities for managing the impacts and dependencies of business upon food, energy, water and the environment. Sustainability Science.

Guan, D. and Hubacek, K. (2007). Assessment of regional trade and virtual water flows in China. Ecological Economics, 61(1):159-170.

Headey, D. (2011). Rethinking the global food crisis: The role of trade shocks. Food Policy, 36(2):136-146.

Heckmann, I., Comes, T., and Nickel, S. (2015). A critical review on supply chain risk Definition, measure and modeling. Omega, 52:119-132.

Hendrickson, C., Horvath, A., Joshi, S., and Lave, L. (1998). Peer Reviewed: Economic Input-Output Models for Environmental Life-Cycle Assessment. Environmental Science \& Technology, 32(7):184A-191A. Publisher: American Chemical Society.

Heron, T., Prado, P., and West, C. (2018). Global Value Chains and the Governance of 'Embedded' Food Commodities: The Case of Soy. Global Policy, 9(S2):29-37.

Hickel, J. and Kallis, G. (2019). Is Green Growth Possible? New Political Economy, $0(0): 1-18$.

Hoekstra, A. Y. and Mekonnen, M. M. (2011). National water footprint accounts: the green, blue and grey water footprint of production and consumption. Volume 1: main report. Research Report Series. No. 50.

Hoekstra, A. Y., Mekonnen, M. M., Chapagain, A. K., Mathews, R. E., and Richter, B. D. (2012). Global Monthly Water Scarcity: Blue Water Footprints versus Blue Water Availability. PLoS ONE, 7(2):e32688.

Hoekstra, A. Y. and Wiedmann, T. O. (2014). Humanity's unsustainable environmental footprint. Science, 344(6188):1114-1117.

Hoff, H. and Gerten, D. (2015). The land-water-climate nexus - what are links to energy (and how can they be modelled)? 
Hofste, R., Kuzma, S., Walker, S., Sutanudjaja, E., Bierkens, M., Kuijper, M., Sanchez, M., van Beek, R., Wada, Y., Galvis, S., and Reig, P. (2019). Aqueduct 3.0: updated decisionrelevant global water risk indicators. Technical report, World Resources Institute.

Houyou, Z., Bielders, C. L., Benhorma, H. A., Dellal, A., and Boutemdjet, A. (2016). Evidence of Strong Land Degradation by Wind Erosion as a Result of Rainfed Cropping in the Algerian Steppe: A Case Study at Laghouat. Land Degradation \& Development, 27(8):1788-1796.

Hubacek, K. and Feng, K. (2016). Comparing apples and oranges: Some confusion about using and interpreting physical trade matrices versus multi-regional input-output analysis. Land Use Policy, 50:194-201.

IEA (2019). Statistics Resources: Key resources for energy statisticians and IEA data users [Questionnaires]. Technical report.

IPBES (2018). The IPBES Assessment Report on Land Degradation and Restoration. Technical report.

IPCC, editor (2014). Climate change 2014: mitigation of climate change: Working Group III contribution to the Fifth Assessment Report of the Intergovernmental Panel on Climate Change. Cambridge University Press, New York, NY. OCLC: ocn892580682.

Isard, W. (1951). Interregional and Regional Input-Output Analysis: A Model of a SpaceEconomy. The Review of Economics and Statistics, 33(4):318-328. Publisher: The MIT Press.

Jacobs, C. and van Klooster, K. (2012). Water and agriculture in the MaghrebAlterra. Technical report, Wageningen.

Jepson, W. E., Wutich, A., Colllins, S. M., Boateng, G. O., and Young, S. L. (2017). Progress in household water insecurity metrics: a cross-disciplinary approach. WIREs Water, 4(3):e1214. _eprint: https://onlinelibrary.wiley.com/doi/pdf/10.1002/wat2.1214.

Johnson, N., Burek, P., Byers, E., Falchetta, G., Flörke, M., Fujimori, S., Havlik, P., Hejazi, M., Hunt, J., Krey, V., Langan, S., Nakicenovic, N., Palazzo, A., Popp, A., Riahi, K., van Dijk, M., van Vliet, M. T. H., van Vuuren, D. P., Wada, Y., Wiberg, D., Willaarts, B., Zimm, C., and Parkinson, S. (2019). Integrated Solutions for the Water-Energy-Land Nexus: Are Global Models Rising to the Challenge? Water, 11(11):2223. Number: 11 Publisher: Multidisciplinary Digital Publishing Institute.

Kamsamrong, J. and Sorapipatana, C. (2014). An assessment of energy security in Thailand's power generation. Sustainable Energy Technologies and Assessments, 7:45-54.

Kander, A., Jiborn, M., Moran, D. D., and Wiedmann, T. O. (2015). National greenhouse-gas accounting for effective climate policy on international trade. Nature Climate Change, 5(5):431-435. 
Keskinen, M., Guillaume, J. H. A., Kattelus, M., Porkka, M., Räsänen, T. A., and Varis, O. (2016). The Water-Energy-Food Nexus and the Transboundary Context: Insights from Large Asian Rivers. Water, 8(5):193.

Krausmann, F., Gingrich, S., Eisenmenger, N., Erb, K.-H., Haberl, H., and Fischer-Kowalski, M. (2009). Growth in global materials use, GDP and population during the 20th century. Ecological Economics, 68(10):2696-2705.

Krausmann, F., Lauk, C., Haas, W., and Wiedenhofer, D. (2018). From resource extraction to outflows of wastes and emissions: The socioeconomic metabolism of the global economy, 1900-2015. Global Environmental Change, 52:131-140.

Krausmann, F., Weisz, H., and Eisenmenger, N. (2016). Transitions in Sociometabolic Regimes Throughout Human History. In Haberl, H., Fischer-Kowalski, M., Krausmann, F., and Winiwarter, V., editors, Social Ecology: Society-Nature Relations across Time and Space, Human-Environment Interactions, pages 63-92. Springer International Publishing, Cham.

Krausmann, F., Wiedenhofer, D., Lauk, C., Haas, W., Tanikawa, H., Fishman, T., Miatto, A., Schandl, H., and Haberl, H. (2017). Global socioeconomic material stocks rise 23-fold over the 20th century and require half of annual resource use. Proceedings of the National Academy of Sciences, 114(8):1880-1885.

Kumar, M. D. and Singh, O. P. (2005). Virtual Water in Global Food and Water Policy Making: Is There a Need for Rethinking? Water Resources Management, 19(6):759_ 789.

Kumar, P. (2015). Hydrocomplexity: Addressing water security and emergent environmental risks. Water Resources Research, 51(7):5827-5838.

Lacirignola, C., Capone, R., Debs, P., El Bilali, H., and Bottalico, F. (2014). Natural resources - food nexus: food-related environmental footprints in the mediterranean countries. Frontiers in Nutrition, 1:23.

Lambin, E. F. and Meyfroidt, P. (2011). Global land use change, economic globalization, and the looming land scarcity. Proceedings of the National Academy of Sciences, 108(9):3465-3472.

Le, T.-H., Chang, Y., Taghizadeh-Hesary, F., and Yoshino, N. (2019). Energy insecurity in Asia: A multi-dimensional analysis. Economic Modelling, 83:84-95.

Leck, H., Conway, D., Bradshaw, M., and Rees, J. (2015). Tracing the Water-EnergyFood Nexus: Description, Theory and Practice: Tracing the Water-Energy-Food Nexus. Geography Compass, 9(8):445-460.

Lenzen, M. (2008). Double-Counting in Life Cycle Calculations. Journal of Industrial Ecology, 12(4):583-599. 
Lenzen, M. (2009). Understanding virtual water flows: A multiregion input-output case study of Victoria. Water Resources Research, 45(9):W09416.

Lenzen, M., Kanemoto, K., Moran, D., and Geschke, A. (2012). Mapping the Structure of the World Economy. Environmental Science \& Technology, 46(15):8374-8381.

Lenzen, M., Moran, D., Bhaduri, A., Kanemoto, K., Bekchanov, M., Geschke, A., and Foran, B. (2013a). International trade of scarce water. Ecological Economics, 94:78-85.

Lenzen, M., Moran, D., Kanemoto, K., and Geschke, A. (2013b). Building EORA: a global multi-region input-output database at high country and sector resolution. Economic Systems Research, 25(1):20-49.

Leontief, W. and Strout, A. (1963). Multiregional input-output analysis. In Structural Interdependence and Economic Development, pages 119-149. Macmillan, London, United Kingdom.

Li, M., Wiedmann, T., and Hadjikakou, M. (2019). Towards meaningful consumptionbased planetary boundary indicators: The phosphorus exceedance footprint. Global Environmental Change, 54:227-238.

Liu, J., Mooney, H., Hull, V., Davis, S. J., Gaskell, J., Hertel, T., Lubchenco, J., Seto, K. C., Gleick, P., Kremen, C., and Li, S. (2015). Systems integration for global sustainability. Science, 347(6225):1258832.

Long, Y., Yoshida, Y., and Dong, L. (2017). Exploring the indirect household carbon emissions by source: Analysis on 49 Japanese cities. Journal of Cleaner Production, 167:571-581.

Los, B., Timmer, M. P., and de Vries, G. J. (2015). How global are global value chains? A new approach to measure international fragmentation. Journal of Regional Science, 55(1):66-92.

López, L. A., Arce, G., Kronenberg, T., and Rodrigues, J. F. D. (2018). Trade from resourcerich countries avoids the existence of a global pollution haven hypothesis. Journal of Cleaner Production, 175:599-611.

MacDonald, G. K., Brauman, K. A., Sun, S., Carlson, K. M., Cassidy, E. S., Gerber, J. S., and West, P. C. (2015). Rethinking agricultural trade relationships in an era of globalization, volume 65 .

Maddison, A. (2001). The world economy: a millennial perspective. Development Centre studies. Development Centre of the Organisation for Economic Co-operation and Development, Paris, France.

Mateo-Sagasta, J. and Salian, P. (2012). Global database on municipal wastewater production, collection, treatment, discharge and direct use in agriculture. Technical report, UN Food and Agriculture Organization. 
Mekonnen, M. and Hoekstra, A. (2016). Four billion people facing severe water scarcity textbar Science Advances.

Miller, R. E. and Blair, P. D. (2009). Input-Output Analysis: Foundations and Extensions. Cambridge University Press, Cambridge, 2 edition.

Moran, D., Giljum, S., Kanemoto, K., and Godar, J. (2020). From Satellite to Supply Chain: New Approaches Connect Earth Observation to Economic Decisions. One Earth, 3(1):5-8.

Morin, J., Blümer, D., Brandi, C., and Berger, A. (2019). Kick-starting diffusion: Explaining the varying frequency of $<$ span style="font-variant:small-caps;" $>\mathrm{PTA}</$ span $>$ s' environmental clauses by their initial conditions. The World Economy.

Månsson, A., Johansson, B., and Nilsson, L. J. (2014). Assessing energy security: An overview of commonly used methodologies. Energy, 73:1-14.

OECD (2003). Glossary of statistical terms: satellite accounts. Technical report.

Otto, I. M., Biewald, A., Coumou, D., Feulner, G., Köhler, C., Nocke, T., Blok, A., Gröber, A., Selchow, S., Tyfield, D., Volkmer, I., Schellnhuber, H. J., and Beck, U. (2015). Socioeconomic data for global environmental change research. Nature Climate Change, 5:503-506.

Owen, A., Scott, K., and Barrett, J. (2018). Identifying critical supply chains and final products: An input-output approach to exploring the energy-water-food nexus. Applied Energy, 210:632-642.

O'Neill, D. W., Fanning, A. L., Lamb, W. F., and Steinberger, J. K. (2018). A good life for all within planetary boundaries. Nature Sustainability, 1(2):88-95.

Peng, K., Zou, Z., Wang, S., Chen, B., Wei, W., Wu, S., Yang, Q., and Li, J. (2019). Interdependence between energy and metals in China: evidence from a nexus perspective. Journal of Cleaner Production, 214:345-355.

SEI (2012). Integrating the WEAP and LEAP systems to support planning and analysis at the water-energy nexus. Technical report, Stockholm Environment Institute, Sommerville, USA.

Seppelt, R., Manceur, A. M., Liu, J., Fenichel, E. P., and Klotz, S. (2014). Synchronized peak-rate years of global resources use. Ecology and Society, 19(4).

Siegfried, T. U., Fishman, R., Modi, V., and Lall, U. (2008). An Entitlement Approach to Address the Water-Energy-Food Nexus in Rural India. AGU Fall Meeting Abstracts, 11.

Snyder, L. V., Atan, Z., Peng, P., Rong, Y., Schmitt, A. J., and Sinsoysal, B. (2016). OR/MS models for supply chain disruptions: a review. IIE Transactions, 48(2):89-109. 
Srivastava, S., Allouche, J., and Allouche, J. (2017). The resource nexus in an uncertain world: A non-equilibrium perspective. Publication Title: Routledge Handbook of the Resource Nexus.

Srivastava, S. and Lyla, M. (2014). Not Another Nexus? Critical Thinking on the New Security Convergence in Energy, Food, Climate and Water. Technical report, STEPS.

Staupe-Delgado, R. (2019). The water-energy-food-environmental security nexus: moving the debate forward. Environment, Development and Sustainability.

Steffen, W., Broadgate, W., Deutsch, L., Gaffney, O., and Ludwig, C. (2015). The trajectory of the Anthropocene: The Great Acceleration. The Anthropocene Review, 2(1):81-98.

Stirling, A. (2015). Developing 'Nexus Capabilities': towards transdisciplinary methodologies. Technical report, The Nexus Network.

Suh, S., Lenzen, M., Treloar, G. J., Hondo, H., Horvath, A., Huppes, G., Jolliet, O., Klann, U., Krewitt, W., Moriguchi, Y., Munksgaard, J., and Norris, G. (2004). System Boundary Selection in Life-Cycle Inventories Using Hybrid Approaches. Environmental Science \& Technology, 38(3):657-664.

Sušnik, J. (2018). Data-driven quantification of the global water-energy-food system. Resources, Conservation and Recycling, 133:179-190.

Taherzadeh, O. (2019). Gap assessment between international trade agreements (2008-2018) and the SDGs. type: dataset.

Taherzadeh, O., Bithell, M., and Richards, K. (2018). When defining boundaries for nexus analysis, let the data speak. Resources, Conservation and Recycling, 137:314-315.

Taherzadeh, O. and Caro, D. (2019). Drivers of water and land use embodied in international soybean trade. Journal of Cleaner Production, 223:83-93.

Timmer, M. P., Dietzenbacher, E., Los, B., Stehrer, R., and Vries, G. J. d. (2015). An Illustrated User Guide to the World Input-Output Database: the Case of Global Automotive Production. Review of International Economics, 23(3):575-605.

Tukamuhabwa, B. R., Stevenson, M., Busby, J., and Zorzini, M. (2015). Supply chain resilience: definition, review and theoretical foundations for further study. International Journal of Production Research, 53(18):5592-5623.

Tukker, A., Bulavskaya, T., Giljum, S., de Koning, A., Lutter, S., Simas, M., Stadler, K., and Wood, R. (2016). Environmental and resource footprints in a global context: Europe's structural deficit in resource endowments. Global Environmental Change, 40:171-181.

Tukker, A. and Dietzenbacher, E. (2013). Global Multiregional Input-Output Frameworks: An Introduction and Outlook. Economic Systems Research, 25(1):1-19. 
Tuninetti, M., Tamea, S., and Dalin, C. (2019). Water Debt Indicator Reveals Where Agricultural Water Use Exceeds Sustainable Levels. Water Resources Research, 55(3):24642477.

UN, European Commission, IMF, and OECD, editors (2009). System of national accounts 2008. United Nations, New York.

University, Y. (2019). Environmental Performance Index: Agriculture. Technical report.

Vanham, D., Hoekstra, A. Y., Wada, Y., Bouraoui, F., de Roo, A., Mekonnen, M. M., van de Bund, W. J., Batelaan, O., Pavelic, P., Bastiaanssen, W. G. M., Kummu, M., Rockström, J., Liu, J., Bisselink, B., Ronco, P., Pistocchi, A., and Bidoglio, G. (2018). Physical water scarcity metrics for monitoring progress towards SDG target 6.4: An evaluation of indicator 6.4.2 "Level of water stress". Science of The Total Environment, 613-614:218-232.

Varsei, M., Soosay, C., Fahimnia, B., and Sarkis, J. (2014). Framing sustainability performance of supply chains with multidimensional indicators. Supply Chain Management: An International Journal.

Veiga, J. P. S., Malik, A., Lenzen, M., Ferreira Filho, J. B. d. S., and Romanelli, T. L. (2018). Triple-bottom-line assessment of São Paulo state's sugarcane production based on a Brazilian multi-regional input-output matrix. Renewable and Sustainable Energy Reviews, 82:666-680.

Velázquez, E., Madrid, C., and Beltrán, M. J. (2010). Rethinking the Concepts of Virtual Water and Water Footprint in Relation to the Production-Consumption Binomial and the Water-Energy Nexus. Water Resources Management, 25(2):743-761.

Victor, P. A. and Rosenbluth, G. (2007). Managing without growth. Ecological Economics, 61(2-3):492-504.

Vivanco, D. F., Wang, R., and Hertwich, E. (2018a). Nexus Strength: A Novel Metric for Assessing the Global Resource Nexus. Journal of Industrial Ecology, 22(6):1473-1486.

Vivanco, D. F., Wang Ranran, Deetman Sebastiaan, and Hertwich Edgar (2018b). Unraveling the Nexus: Exploring the Pathways to Combined Resource Use. Journal of Industrial Ecology, 0(0).

Vivoda, V. (2010). Evaluating energy security in the Asia-Pacific region: A novel methodological approach. Energy Policy, 38(9):5258-5263.

Vollmer, D., Regan, H. M., and Andelman, S. J. (2016). Assessing the sustainability of freshwater systems: A critical review of composite indicators. Ambio, 45(7):765-780.

Vörösmarty, C. J., Hoekstra, A. Y., Bunn, S. E., Conway, D., and Gupta, J. (2015). Fresh water goes global. Science, 349(6247):478-479. 
Wang, J., Rothausen, S. G. S. A., Conway, D., Zhang, L., Xiong, W., Holman, I. P., and Li, Y. (2012). China's water-energy nexus: greenhouse-gas emissions from groundwater use for agriculture. Environmental Research Letters, 7(1):014035.

Wang, R. and Zimmerman, J. (2016). Hybrid Analysis of Blue Water Consumption and Water Scarcity Implications at the Global, National, and Basin Levels in an Increasingly Globalized World. Environmental Science \& Technology, 50(10):5143-5153.

WaterStat (2019). WaterStat - water footprint statistics. Technical report.

WEF (2019). The Global Risks Report 2019. Technical report, World Economic Forum.

Weitz, N., Strambo, C., Kemp-Benedict, E., and Nilsson, M. (2017). Closing the governance gaps in the water-energy-food nexus: Insights from integrative governance. Global Environmental Change, 45:165-173.

White, D. J., Hubacek, K., Feng, K., Sun, L., and Meng, B. (2018). The Water-EnergyFood Nexus in East Asia: A tele-connected value chain analysis using inter-regional input-output analysis. Applied Energy, 210:550-567.

Wichelns, D. (2017). The water-energy-food nexus: Is the increasing attention warranted, from either a research or policy perspective? Environmental Science \& Policy, 69:113123.

Wiedmann, T. and Lenzen, M. (2018). Environmental and social footprints of international trade, volume 11. Springer US.

Wilting, H. C., Schipper, A. M., Bakkenes, M., Meijer, J. R., and Huijbregts, M. A. J. (2017). Quantifying Biodiversity Losses Due to Human Consumption: A Global-Scale Footprint Analysis. Environmental Science \& Technology, 51(6):3298-3306.

Wood, R., Stadler, K., Bulavskaya, T., Lutter, S., Giljum, S., de Koning, A., Kuenen, J., Schütz, H., Acosta-Fernández, J., Usubiaga, A., Simas, M., Ivanova, O., Weinzettel, J., Schmidt, J. H., Merciai, S., and Tukker, A. (2014). Global Sustainability Accounting-Developing EXIOBASE for Multi-Regional Footprint Analysis. Sustainability, 7(1):138-163.

Wood, R., Stadler, K., Simas, M., Bulavskaya, T., Giljum, S., Lutter, S., and Tukker, A. (2018). Growth in Environmental Footprints and Environmental Impacts Embodied in Trade: Resource Efficiency Indicators from EXIOBASE3. Journal of Industrial Ecology, 22(3):553-564.

WRI (2015). Aqueduct Projected Water Stress Country Rankings. Technical report.

Wutich, A. and Brewis, A. (2014). Food, Water, and Scarcity: Toward a Broader Anthropology of Resource Insecurity. Current Anthropology, 55(4):444-468. Publisher: The University of Chicago Press. 
Xu, Z., Chau, S. N., Ruzzenenti, F., Connor, T., Li, Y., Tang, Y., Li, D., Gong, M., and Liu, J. (2019). Evolution of multiple global virtual material flows. Science of The Total Environment, 658:659-668.

Zanten, H. H. E. v., Mollenhorst, H., Klootwijk, C. W., Middelaar, C. E. v., and Boer, I. J. M. d. (2016). Global food supply: land use efficiency of livestock systems. The International Journal of Life Cycle Assessment, 21(5):747-758.

Zhang, Q., Jiang, X., Tong, D., Davis, S. J., Zhao, H., Geng, G., Feng, T., Zheng, B., Lu, Z., Streets, D. G., Ni, R., Brauer, M., van Donkelaar, A., Martin, R. V., Huo, H., Liu, Z., Pan, D., Kan, H., Yan, Y., Lin, J., He, K., and Guan, D. (2017). Transboundary health impacts of transported global air pollution and international trade. Nature, 543(7647):705-709.

Zhang, X. and Davidson, E. (2016). Sustainable Nitrogen Management Index (SNMI): methodology. Technical report.

Zhang, X., Davidson, E. A., Mauzerall, D. L., Searchinger, T. D., Dumas, P., and Shen, Y. (2015). Managing nitrogen for sustainable development. Nature, 528(7580):51-59.

Zhou, F., Bo, Y., Ciais, P., Dumas, P., Tang, Q., Wang, X., Liu, J., Zheng, C., Polcher, J., Yin, Z., Guimberteau, M., Peng, S., Ottle, C., Zhao, X., Zhao, J., Tan, Q., Chen, L., Shen, H., Yang, H., Piao, S., Wang, H., and Wada, Y. (2020). Deceleration of China's human water use and its key drivers. Proceedings of the National Academy of Sciences, 117(14):7702-7711. 